\title{
MINERALIZAÇÃO DE NITROGÊNIO EM ECOSSISTEMAS FLORESTAIS NATURAIS E IMPLANTADOS DO ESTADO DE SÃO PAULO
}

\author{
KATHYA CILENE FERRITE SORBELINI MENDES \\ Engenheira Florestal
}

ORIENTADOR: PROF DR JOSÉ LEONARDO DE MORAES GONÇALVES

Dissertação apresentada à Escola Superior de Agricultura "Luiz de Queiroz", Universidade de São Paulo, para obtenção do título de Mestre em Engenharia Florestal, Área de Concentração: Ciências Florestal.

PIRACICABA

Estado de São Paulo - Brasil

Maio - 1999 
Dados Internacionais de Catalogação na Publicação (CIP)

DIVISÃO DE BIBLIOTECA E DOCUMENTAÇĀO - Campus "Luiz de Queiroz"/USP

Mendes, Kathya Cilene Ferrite Sorbelini

Mineração de nitrogênio em ecossistemas florestais naturais e implantados do

Estado de São Paulo / Kathya Cilene Ferrite Sorbelini Mendes. - - Piracicaba, 1999.

$39 \mathrm{p}$.

Dissertação (mestrado) - Escola Superior de Agricultura Luiz de Queiroz, 1999.

Bibliografia.

1. Cerrado 2. Ecologia florestal 3. Ecossistema florestal 4. Floresta 5. Mata

Atlântica 6. Mineralização 7. Nitrogênio I. Título

CDD 634.94

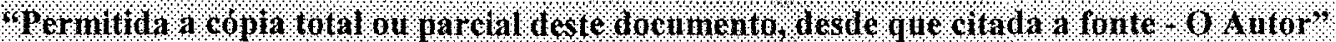




\begin{abstract}
À minha mãe pelo amor e carinho sempre presentes, ao meu pai pela confiança e por me incentivar a perseguir meus objetivos com afinco e ao meu irmão Leonardo pela sua inestimável amizade
\end{abstract}

\title{
OFEREÇO
}

À minha avó Idalina pờr súa lucidez, determinação, coragem e amor à vida, que a tornaram um exemplo a ser seguido

DEDICO 


\section{AGRADECIMENTOS}

A DEUS por estar sempre presente em meu coração me orientando e ajudando a superar todas as adversidades.

Ao meu orientador Prof Dr. José Leonardo de Moraes Gonçalves, pelo incentivo, apoio, dedicação e amizade dispensada em todo o transcorrer do trabalho.

As empresas DURATEX, SUZANO, VCP e RIPASA, nas pessoas do Eng. Raul Chaves e técnico José Carlos, Eng. José Luiz Gava e técnico J R S Freitas, Eng Celina Ferraz Valle e técnico Walmir Franciscatti e Eng Rogério Salamuni e técnico Juarez Rodrigues de Lima, respectivamente.

Ao PSTM pelo apoio logistico e financeiro e a seu coordenador temático Vanderlei Benedetti pela dedicação e empenho para resolver todos os problemas.

Ao LEA, em especial a Alba Valéria Masetto, Fernanda e Juliana e a todos os funcionários e estagiários que tornaram mais amena a realização desta tarefa.

Ao Viveiro do Departamento de Ciência Florestais, especialmente ao técnico José Amarildo da Fonseca e Ivan que acompanharam de perto as etapas de coleta do materai de pesquisa.

Aos colegas Cassiano M. Sasaki e Sérgio Ricardo Bentevinha pela dedicação e amizade dispensada

As amigas Ana Claudia de Lira, Michelle Nazaré Xavier da Costa e Viviane Soccio Monteiro pelo apoio recebido e por todos os momentos que compartilhamos juntas.

Aos amigos do Curso de Pós-Graduação e a todos que diretamente ou indiretamente participaram e tornaram essa tarefa possível. 


\section{SUMÁRIO}

Página

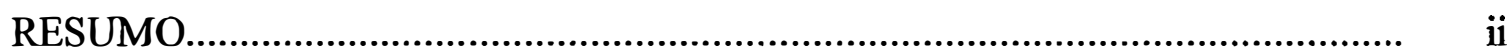

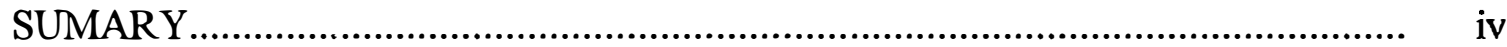

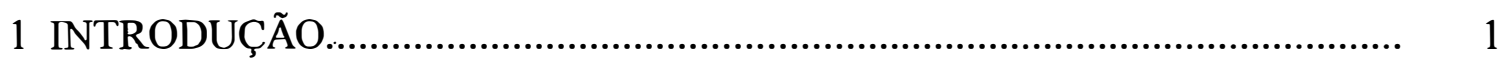

2 REVISÃO DE LITERATURA........................................................................... 4

3 MATERIAL E MÉTODOS.......................................................................... 9

3.1 Locais, características ambientais e coberturas florestais das áreas experimentais............................................................................................... 9

3.2 Caracterização química e física do solo.......................................................... 11

3.3 Mineralização de nitrogênio sob condições de laboratório.................................. 13

3.3.1 Mineralização aeróbica de nitrogênio........................................................... 13

3.3.2 Mineralização anaeróbica de nitrogênio......................................................... 14

3.4 Análise estatística e interpretação dos dados................................................... 15

4 RESULTADOS E DISCUSSÃO .................................................................... 17

4.1 Cinética de mineralização e estimativa do nitrogênio potencialmente mineralizável.

4.2 Efeito da cobertura vegetal sobre as formas e as quantidades de nitrogênio potencialmente mineralizável................................................................................ 24

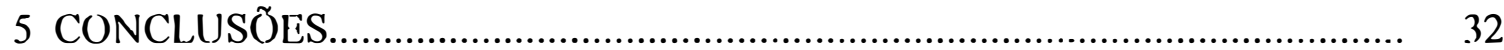

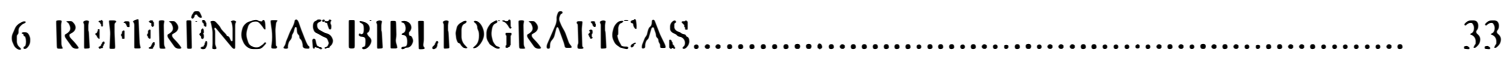




\title{
MINERALIZAÇÃO DE NITROGÊNIO EM ECOSSISTEMAS FLORESTAIS NATURAIS E IMPLANTADOS DO ESTADO DE SÃO PAULO:
}

\author{
AUTOR: KATHYA CILENE FERRITE SORBELINI MENDES \\ ORIENTEDOR: Prof. Dr. JOSÉ LEONARDO DE MORAES GONÇALVES
}

\section{RESUMO}

No presente estudo foram usados povoamentos homogêneos de Eucalyptus grandis e Pinus caribaea var. hondurensis, em diferentes estágios de crescimento, bem como fragmentos de florestas naturais de Cerrado e Mata Atlântica. As condições edafoclimáticas e florísticas das áreas escolhidas são representativas das matas nativas e plantações florestais estabelecidos no planalto ocidental paulista. Amostras de solo (0-5 e 5-15 cm) foram incubados por períodos sucessivos de 3, 3, 4, 4, 6 e 10 semanas num total de 30 semanas, sob condições aeróbicas e anaeróbicas, em laboratório. As quantidades acumuladas de $\mathrm{N}$ mineralizado, em condições aeróbicas e anaeróbicas, mostrou uma relação exponencial com o tempo de incubação. A equação $\mathrm{N}_{t}=\mathrm{N}_{0}+b / t$ ajustou-se melhor aos dados do que a equação proposta por Stanford \& Smith (1972), $N_{t}$ $=\mathrm{N}_{0}\left(1-\mathrm{e}^{-\mathrm{kt}}\right)$, onde $\mathrm{N}_{0}$ é o $\mathrm{N}$ potencialmente mineralizável, $\mathrm{N}_{\mathrm{t}}$ são as quantidades acumuladas de $\mathrm{N}$ mineralizado e $\mathrm{t}$ é o tempo de mineralização. Esta equação superestimou os valores de $\mathrm{N}_{0}$ em vários sítios e condições de incubação, além de não modelar-se adequadamente aos dados. Sugere-se o uso da primeira equação para modelar a cinética de mineralização de $\mathrm{N}$. As taxas de mineralização de $\mathrm{N}$ estabilizaram após 8 a 15 semanas de incubação. As quantidades totais de $\mathrm{N}_{0}$ (camada $0-15 \mathrm{~cm}$ ), sob condições aeróbicas, foram em média de $103 \pm 53 \mathrm{~kg} \mathrm{ha}^{-1} \mathrm{de} \mathrm{N} \mathrm{e}$, sob condições anaeróbicas, em média de $281 \pm 175 \mathrm{~kg} \mathrm{ha}^{-1}$ de $\mathrm{N}$. Admite-se que os valores de $\mathrm{N}_{0}$ obtidos aerobicamente estão subestimados, provavelmente em função: a) de potenciais efeitos nocivos da lixiviação periódica do solo com solução salina $\left(\mathrm{CaCl}_{2} 0,01 \mathrm{~mol} \mathrm{~L}^{-1}\right)$ sobre a atividade das 
comunidades microbianas dos solos e b) remoção, com as lixiviações, de grande quantidade de N-orgânico solúvel, potencialmente mineralizável. Por se constituírem em características da atividade biológica, física e química do solo, a cinética de mineralização de $\mathrm{N}$ e o $\mathrm{N}_{0}$ são índices importantes para avaliar a dinâmica do $\mathrm{N}$ em ecossistemas florestais, assim como podem constituir bons indicativos da sustentabilidade da produtividade florestal e qualidade ambiental. Estimou-se que as reservas médias de $\mathrm{N}$ dos sítios pesquisados sejam suficientes para 3 a 5 rotações de cultivo ( 7 anos cada) de $E$. grandis. No fim deste período, é provável que as respostas à adubação nitrogenada sejam bastante significativas. Em alguns sítios, a presença da mata nativa redundou em maiores quantidades de $\mathrm{N}$ potencialmente mineralizável $\left(\mathrm{N}_{0}\right)$. Por exemplo, o $\mathrm{N}_{0}$ estimado num

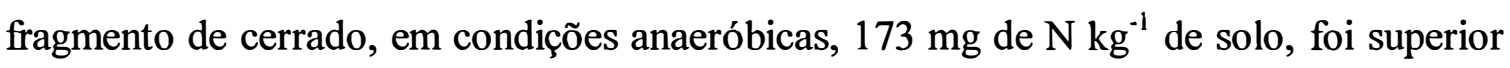
ao obtido num florestamento de Pinus caribaea var. hondurensis, recém implantado, 44 mg de $\mathrm{N} \mathrm{kg}^{-1}$ de solo, o qual foi semelhante ao $\mathrm{N}_{0}$ obtido em um florestamento de Pinus caribaea var. hondurensis, com 20 anos de idade, $45 \mathrm{mg}$ de $\mathrm{N} \mathrm{kg}^{-1}$ de solo. Num fragmento de Cerradão e numa brotação de. Eucalyptus grandis com 7 anos de idade, as quantidades de $\mathrm{N}_{0}$ foram muito superiores a de um povoamento de Eucalyptus grandis, recém reformado ( 0,3 ano de idade). Esses resultados destacam o grande o efeito de florestas adultas sobre os estoques de $\mathrm{N}_{0}$, principalmente devido as grandes quantidades de $\mathrm{N}$ cicladas biogeoquimicamente. A floresta adulta de eucalipto foi capaz de manter no solo níveis de $\mathrm{N}_{0}$ similares ao da floresta nativa. A razão média $\mathrm{N}-\mathrm{NH}_{4}{ }^{+}: \mathrm{N}^{-} \mathrm{NO}_{3}{ }^{-}$, quando se considera todos os sítios, foi igual a $4: 1$ sob condições aeróbicas. A predominância de $\mathrm{N}-\mathrm{NH}_{4}{ }^{+}$em solos sob florestas tem como uma das causas fundamentais o baixo nível de fertilidade dos solos e elevados índices de acidez do solo, inadequados para a atividade das bactérias nitrificadoras. Tomando-se por base as razões $N_{0} / N_{t}\left(N_{t}\right.$ é o $N$ total do solo), deduziu-se que apenas 5 a $15 \%$ do teor de matéria orgânica do solo é decomponível. Essta variação dependeu das características do solo, principalmente aquelas relacionadas com o teor c qualidade da matéria orgânica do solo (MOS) e sua textura. 


\title{
NITROGEN MINERALIZATION IN NATURAL AND FOREST PLANTATION ECOSYSTEMS OF SÃO PAULO STATE.
}

\author{
Author: KATHYA CILENE FERRITE SORBELINI MENDES \\ Adviser: Prof. Dr. JOSÉ LEONARDO DE MORAES GONÇALVES
}

SUMMARY

In the present study homogeneous stands of Eucalyptus grandis and Pinus caribaea var. hondurensis in different growth stages as well as fragments of natural vegetation of "Cerrado" and Atlantic Forest were used. The climatic, edaphic and floristic conditions of the chosen areas are representative of the native forests and forest plantations established at the western plateau of São Paulo state. Soil samples (0-5 and 5$15 \mathrm{~cm})$ were incubated under aerobic and anaerobic laboratory conditions by successive periods of $3,3,4,4,6$ and 10 weeks in a total of 30 weeks. In both conditions, the accumulated amounts of mineralized $\mathrm{N}$ an exponential relationship with the incubation time was showed. The equation $\mathrm{N}_{\mathrm{t}}=\mathrm{N}_{0}+\mathrm{b} / \mathrm{t}$ was better adjusted to the data the equation proposed by Stanford \& Smith (1972), $\mathrm{N}_{\mathrm{t}}=\mathrm{N}_{0}\left(1-\mathrm{e}^{-\mathrm{kt}}\right)$, where $\mathrm{N}_{0}$ are potentially mineralizable $\mathrm{N}, \mathrm{N}_{\mathrm{t}}$ is the accumulated amount of mineralized $\mathrm{N}$ and $\mathrm{t}$ is the time of mineralization. This equation overestimated the values of $\mathrm{N}_{0}$ in several sites and incubation conditions, besides not modeling appropriately to the data. The use of the first equation to model the $\mathrm{N}$ mineralization kinetics is suggested. The $\mathrm{N}$ mineralization rates stabilized after 8 to 15 weeks of incubation. Under aerobic conditions, the total amounts of $\mathrm{N}_{0}$ (layer 0-15 cm) were on the average of $103 \pm 53 \mathrm{~kg} \mathrm{ha}^{-1}$ of $\mathrm{N}$, and under anaerobic conditions, on the average of $281 \pm 175 \mathrm{~kg} \mathrm{ha}^{-1}$ of $\mathrm{N}$. Admitting that the $\mathrm{N}_{0}$ values obtained aerobically are underestimated, some of the main reasons are: a) the potential harmful effects of soil leaching with saline solution $\left(\mathrm{CaCl}_{2} 0,01 \mathrm{~mol} \mathrm{~L}^{-1}\right)$ on the microbial 
communities and b) removal of great amount of $\mathrm{N}$-organic soluble, potentially mineralizable, by leaching. Being characteristics of the physical, chemical and biological activity of the soil, the $\mathrm{N}$ mineralization kinetics and $\mathrm{N}_{0}$ are important indexes to evaluate the $\mathrm{N}$ dynamics in forest ecosystems as well as it can constitute good indicative of the forest yield sustainability and environmental quality. The medium pools of $\mathrm{N}$ of the researched sites was estimated to be enough for 3 to 5 cultivation rotations ( 7 years each) of $E$. grandis. At the end of this period, response to $\mathrm{N}$ fertilization is probable being quite significant. At some sites larger amounts of potentially mineralizable $\mathrm{N}\left(\mathrm{N}_{0}\right)$ were verified on presence of the native forest. For instance, under anaerobic conditions, the $\mathrm{N}_{0}$ estimated in a fragment of Brazilian savanna, $173 \mathrm{mg}$ of $\mathrm{N} \mathrm{kg}^{-1}$ of soil, was higher than that obtained in a Pinus caribaea var. hondurensis stand recently established, $44 \mathrm{mg}$ of $\mathrm{N}$ $\mathrm{kg}^{-1}$ of soil, which was similar to the $\mathrm{N}_{0}$ obtained in a Pinus caribaea var. hondurensis stand with 20 years of age, $45 \mathrm{mg}$ of $\mathrm{N} \mathrm{kg}^{-1}$ of soil. The amounts of $\mathrm{N}_{0}$ estimated at a $E$. grandis stand recently reestablished ( 0,3 year-old) was much lower than that estimated in a fragment of Brazilian savanna cold "Cerradão" and in Eucalyptus grandis coppice with 7 years-old. These results emphasize the high effect of adult forests on the $\mathrm{N}_{0}$ pools, mainly due to the great amounts of $\mathrm{N}$ biogeochemically cycled. The adult forest of eucalypti was able to maintain similar $\mathrm{N}_{0}$ levels got on native forests. The mean $\mathrm{N}^{-\mathrm{NH}_{4}}{ }^{+}$: $\mathrm{N}-\mathrm{NO}_{3}{ }^{-}$ratio was equal to 4:1 under aerobic conditions when all the sites are taken in accounting. The $\mathrm{N}-\mathrm{NH}_{4}{ }^{+}$predominance under forest soils has as one of the fundamental causes the low level of fertility and high indexes of soil acidity, inadequate for the activity of nitrifier bacterias. Based on $\mathrm{N}_{0} / \mathrm{N}_{t}$ ratio $\left(\mathrm{N}_{t}\right.$ is total soil $\left.\mathrm{N}\right), 5$ to $15 \%$ of the organic matter $\mathrm{N}$ were found to be decomposable. This range depended on the soil characteristics, mainly those related to soil organic matter (SOM) content and quality and, its texture. 


\section{INTRODUÇÃO}

O Brasil possui atualmente mais de 6 milhões de hectares reflorestados com plantações homogêneas, predominando as espécies do gênero Eucalyptus e Pinus. Essas florestas têm sido estabelecidas em áreas originalmente cobertas por vegetação clímax, do tipo Cerrado e Mata Atlântica. Paralelamente à grande e crescente relevância do setor florestal para o país, admite-se, freqüentemente, que a sustentabilidade da produção das florestas plantadas, a médio e longo prazo, corre sério risco; além disso, pouco se conhece sobre os impactos ambientais ocasionados pela substituição das florestais naturais por plantações florestais homogêneas. Os maiores problemas estão relacionados com a baixa fertilidade e pequenas reservas de nutrientes dos solos usados para fins de reflorestamento, comumente, latossolos de textura média e areias quartzosas. Como agravante, para elevar os índices de produtividade, os sistemas silviculturais usados são muito intensivos, contemplando, inclusive, o plantio de espécies florestais de rápido crescimento, com grande capacidade de extração e exportação de nutrientes (Gonçalves et al. 1997a).

Dentre os fatores edáficos, a dinâmica da matéria orgânica $\mathrm{c}$ do nitrogênio têm importância fundamental, tanto pelas funções que desempenham sobre as características físicas e químicas do solo, còmo em sua atividade biológica. Diante deste tabcla, faz-sc neccssário estudar os processos lísicos, químicos e biológicos que governam a dinâmica dos nutrientes entre $\mathrm{c}$ nos diferentes compartimentos do ecossistema: solo, biomassa aérea e subterrânea. Esclareccndo esses processos, será possível, numa próxima etapa, fazer recomendações técnicas de manejo para esses 
ecossistemas florestais, de forma a permitir que seus estoques de nutrientes sejam racionalizados, tendo por base parâmetros científicos bem compreendidos. As pesquisas relativas a esse tema são raras em outros países com tradição florestal e praticamente inexistentes no Brasil.

Vários métodos para estimar as taxas de mineralização, absorção e lixiviação de $\mathrm{N}$ têm sido propostos a nível de campo e laboratório. Dentre os métodos de campo, destacam-se a incubação seqüencial de colunas de solo pouco perturbadas e em relação aos métodos de laboratório, as incubações aeróbicas e anaeróbicas de amostras de solo

Algumas vantagens do método anaeróbico de mineralização de $\mathrm{N}$ em relação ao método aeróbico foram constatadas por alguns pesquisadores e/ou puderam ser verificadas e deduzidas a partir desta pesquisa: (i) não há problemas relacionados ao estabelecimento de um nível ótimo ou de perdas de umidade durante o período de incubação, (ii) maiores quantidades de $\mathrm{N}$ são mineralizadas num dado período de tempo, (iii) temperaturas mais elevadas podem ser usadas, o que reduz o período de incubação, sem necessidade de se preocupar com a temperatura ideal para os microorganismos nitrificadores, (iv) somente o N-NH${ }_{4}^{+}$precisa ser analisado (Keeney 1982), (v) não há remoção de formas solúveis de $\mathrm{N}$-orgânico durante o processo de lixiviação, como constatado por Gianello et al. (1995), (vi) as soluções salinas usadas para a extração de $\mathrm{N}-\mathrm{NH}_{4}{ }^{+}$são mais concentradas (geralmente $\mathrm{KCl} 2 \mathrm{~mol} \mathrm{~L}^{-1}$ ), assegurando a extração total ou quase total do $\mathrm{N}$ mineralizado, e (vii) as práticas laboratoriais são mais simples e rápidas. As quantidades de $\mathrm{N}$ obtidas por este método tem apresentado boas correlações com as quantidades de $\mathrm{N}$ absorvidas pelas plantas (Keeney \& Bremner, 1966; Sims et al., 1967; Sims \& Blackmon, 1967; Cornforth \& Walmsley, 1971; Ryan et al., 1971; Osborne $\&$ Storrier, 1976). 
O presente estudo teve como objetivos: a) caracterizar a cinética de mineralização de $\mathrm{N}$ e estimar as quantidades de $\mathrm{N}$ potencialmente mineralizável, sob condições aeróbicas e anaeróbicas de laboratório, em plantações homogêneas de eucalipto e pinus, e em áreas cobertas com florestas naturais de Cerrado e Mata Atlântica (Floresta Estacional Semidecidual), localizadas em vários municípios do estado de São Paulo; e b) determinar se o potencial de mineralização de $\mathrm{N}$ é suficiente para suprir as necessidades de nitrogênio dessas plantações florestais. 


\section{REVISÃO DE LITERATURA}

Vários pesquisadores têm observado que raramente as plantações extensivas de florestas respondem à fertilização nitrogenada, sob condições de clima tropical e subtropical (Herbert \& Schönau, 1990; Gonçalves et al., 1997a). Provavelmente, porque dentre as principais fontes de N, deposição pelas águas da chuva, fixação biológica por organismos de vida livre e associados, fertilização e mineralização do $\mathrm{N}$ orgânico ao longo do ciclo da cultura, a última seja a fonte principal e suficiente para atender a demanda das árvores (Gonçalves et al., 1997b) . Contudo, devido às altas taxas de exportação de N (Bellote et al., 1980; Poggiani, 1985; Reis et al., 1987; \& Gonçalves, 1995), as pequenas quantidades de $\mathrm{N}$ aplicadas via fertilização (Barros et al., 1990 e Gonçalves, 1997a), somado ao possível esgotamento das reservas de N orgânico potencialmente mineralizável, espera-se que as florestas manejadas intensivamente respondam à fertilização nitrogenada após vários ciclos de cultivo. $\mathrm{O}$ déficit de $\mathrm{N}$ esta estreitamente relacionado com o esgotamento das fontes de $\mathrm{C}$ facilmente mineralizáveis, já que a dinâmica do $\mathrm{N}$ está intimamente relacionada à do $\mathrm{C}$ (McGill \& Christie, 1983).

Reduções de produtividade entre sucessivas rotações são atribuidas principalmente a perdas de matéria orgânica e nitrogênio durante a exploração e preparação do sítio (Flinn etal.,1980; Woods, 1980; Farrell et al 1981). Flinn et al (1979), citado por Smethurst e Nambiar (1990), estimaram que a exploração e queima em sítios levam a perdas de $423 \mathrm{Kg} \mathrm{N} / \mathrm{ha}$, representando uma redução de $28 \%$ na soma total de $\mathrm{N}$ no solo a profundidade de $50 \mathrm{~cm}$. Perdas estas, que podem comprometer o desenvolvimento de povoamentos florestais implantados. As pesquisas relativas a esse 
tema são raras em outros países com tradição florestal e praticamente inexistentes no Brasil.

As quantias e formas de $\mathrm{N}$ mineral produzidas em solos sob florestas dependem das propriedades fisicas e químicas e principalmente biológicas destes solos (Richards et al, 1985). Alexander (1967) e Black (1968) apontaram como fatores que afetam a intensidade de mineralização o tipo de solo, conteúdo de matéria orgânica e $\mathrm{N}$ total, relação $\mathrm{C} / \mathrm{N}$, tempo de uso dos solos, $\mathrm{pH}$, temperatura, umidade, secamento, congelamento e quantidade de nutrientes inorgânicos e suas interações. Stanford \& Smith (1972), relacionam que a quantidade de $\mathrm{N}$ mineralizado no solo em um dado tempo é função da temperatura, água, taxa de reposição de oxigênio, $\mathrm{pH}$, quantidade e natureza dos resíduos de plantas e nível de outros nutrientes no solo.

Para Richards et al (1985), dentre as propriedades químicas mais importantes destacam-se o $\mathrm{pH}$ e a característica do húmus. Runge (1983), citado por Richards et al (1985) apontou que a produção de $\mathrm{N}$ mineral em solos estava correlacionada positivamente com o conteúdo de $\mathrm{N}$ total e negativamente com a relação $\mathrm{C} / \mathrm{N}$, examinando sempre solos que apresentavam o mesmo tipo de húmus e estavam no mesmo estágio de decomposição. Em solos bem estruturados, onde a matéria orgânica do está bem incorporado à fração mineral do solo, e que geralmente apresentam uma posição alta de cátions, a mineralização de $\mathrm{N}$ orgânico procede rapidamente por toda parte acima do perfil.

A temperatura e a umidade são características fisicas importantes considerando-se o ciclo do nitrogênio. A amonificação ocorre sobre todo limite de temperaturas adequado a atividade biológica $\left(0-70^{\circ} \mathrm{C}\right)$ e devido a divcrsidade fisiológica da microbiota heterotrófica, não é aplicada uma temperatura ótima que possa ser citada universamente. A nitrificação é mais dependente de temperatura, sendo seu ponto ótimo entre 20 e $35^{\circ} \mathrm{C}$, dependendo do tipo de solo e clima. A taxa de mineralização aumenta 
com o incremento da umidade disponível, mas este efeito é neutralizado pelo decréscimo da aeração em solos contendo alta umidade. (Richards et al, 1985).

Dentre outros fatores que contribuem para o fluxo de $\mathrm{N}$ merece destaque o comportamento das populações microbianas do solo que através da sua atividade biológica representam uma importante fonte de N. Estas populações microbianas são consideradas um reservatório quando imobilizam nutrientes para o seu próprio consumo e como fonte quando mineralizam compostos orgânicos, os quais podem ser absorvidos pelas plantas (Paul \& Voroneiy, 1980). Sendo que esta atividade está, intimamente, relacionada às caracteristicas edafoclimáticas.

Vários métodos para estimar as taxas de mineralização, absorção e lixiviação de $\mathrm{N}$ em nível de campo e laboratório têm sido propostos. Dentre os métodos de campo, a incubação sequencial de colunas de solo pouco pertubadas tem sido indicada como o método mais adequado, seja por causar menor distúrbio no solo ou por ser bastante sensível às variações ambientais (Nadelhofer et al., 1983; Binkley \& Hart, 1989; Raison et al., 1987; Whynot \& Weetman, 1991). Dentre os métodos de laboratório, as incubações aeróbicas e anaeróbicas de amostras de solo têm se mostrado promissoras (Stanford \& Smith, 1972;), permitindo a obtenção de índices de N mineralizado, de N potencialmente mineralizável e de taxas de mineralização de $\mathrm{N}$ e $\mathrm{C}$ que se correlacionam com as quantidades de $\mathrm{N}$ absorvidas por plantas (Stanford et. al., 1973). Apesar destes métodos não refletirem as flutuações naturais que ocorrem sob condições de campo (Lamb, 1980 e Hart \& Binkley, 1985), fornecem uma boa estimativa dos "pools" de nitrogênio mineralizável presentes no tempo de amostragem e, permitem estabelecer comparações entre os diferentes sítios de amostragem.

Os modelos de cinética de mineralização de $\mathrm{N}$ tem sido propostos com o principal objetivo de obter índices da disponibilidade de $\mathrm{N}$ para as plantas. Estes modelos permitem estimar a capacidade de suprimento de $\mathrm{N}$ dos solos, as fases de maior 
disponibilidade de $\mathrm{N}$ e a necessidade de adubação nitrogenada de forma simples $\mathrm{e}$ eficiente. Esta tarefa é extremamente difícil, dada a complexidade de fatores que afetam a dinâmica do elemento no ambiente (Black, 1968). os modelos de mineralização devem refletir mudanças na disponibilidade do substrato, atividade microbiológica e balanço entre a mineralização e a imobilização bruta.

Stanford e Smith (1972), propuseram deduzir o N mineralizado através de amostras incubadas de solo, para determinar seu potencial de mineralização $\left(\mathrm{N}_{0}\right)$ e taxa constante de mineralização $(\mathrm{k})$, combinando seus parâmetros com a temperatura e umidade no solo.

Uma abordagem nova do problema foi feita por Stanford \& Smith (1972) e mais recentemente por Hadas et al (1986). Partindo da premissa de que apenas uma parte do N total do solo é potencialmente mineralizavel, Stanford \& Smith (1972) propuseram que esse fenômeno segue a cinética de primeira ordem, ou seja:

$$
\begin{aligned}
& \frac{\mathrm{dN}}{\mathrm{dt}}=-\mathrm{kN} \\
& \text { em que: } \mathrm{N}=\mathrm{N}_{0}-\mathrm{N}_{\mathrm{t}^{\prime}} \\
& \text { sendo: } \\
& \mathrm{N}_{0}=\text { nitrogênio potencialmente mineralizável } \\
& \mathrm{N}_{\mathrm{t}^{\prime}}=\text { nitrogênio mineralizado até o tempo } \mathrm{t} \\
& \mathrm{k}=\text { constante de mineralização }
\end{aligned}
$$

Com isso, pode-se estimar dois parâmetros básicos: a quantidade de $\mathrm{N}$ passível de ser mineralizada $\left(\mathrm{N}_{0}\right)$ e a taxa de mineralização de $N(k)$, de grande importância prática no manejo agronômico do $\mathrm{N}$. O índice $\mathrm{N}_{0}$ seria o fator quantidade e o k o fator intensidade. $\mathrm{O}$ valor de $\mathrm{N}_{0}$, conforme sugerido por Stanford et al (1973), seria independente da temperatura, somente o tempo de incubação exigido para atingi-lo seria 
variável, segundo a temperatura de incubação do solo. A constante de mineralização $\mathrm{k}$ é dependente da temperatura e umidade do solo (Oyanedel e Rodriguez, 1977)

Equações foram desenvolvidas com o objetivo de prever o nitrogênio mineralizado até um tempo $t, \mathrm{~N}_{\mathrm{t}}$, de acordo com as variações semanais ou mensais de temperatura Stanford et al (1973) e umidade (Oyanedel e Rodriguez, 1977). Estas equações conseguiram, em experimentos de campo, prever com erro de $10 \%$ a necessidade de adubação nitrogenada, mostrando que os parâmetros $\mathrm{N}_{0}$ e k são bastante promissores.

Parentoni et al (1988) resalta que vários modelos têm sido propostos e utilizados no estudo da mineralização do N. Resultados encontrados pôr Deans et al (1986) mostraram que o uso de equações de cinética de segunda ordem permitiu estimar o $\mathrm{N}_{0}$ com maior precisão. Mais recentemente, Caski \& Sparts (1987) inseriram estimativas da quantidade final de $\mathrm{N}$ liberado no modelo logarítimo transformado para descrever a extração química do $\mathrm{N}$ mineralizado. A desvantagem da forma logarítimica inclui o requerimento da extrapolação das estimativas de produção inicial ou concentrações finais.

Embora alguns autores tenham relatado valores superestimados do $\mathrm{N}$ potencialmente mineralizado utilizando o método de incubação quando comparados àqueles provenientes do campo (Verstaeten \& Voets, 1976; Cabrera \& Kissel, 1988), outros encontraram resultados bem correlacionados (Stanford et al. 1977, Herli;y, 1979 e Marion et al. 1981). De acordo com Craswell \& Waring (1972) e Hiura et al. (1976), esta superestimativa pode ser devido as amostras serem submetidas ao pré tratamento antes da incubação ( secagem e peneiramento) e/ou pelas condicões físicas da amostra durante a incubação (solo misturado com areia ou vermiculita). 


\section{MATERIAL E MÉTODOS}

3.1 Locais, características ambientais e coberturas florestais das áreas experimentais

As áreas onde foram amostrados os solos para o presente estavam cobertas por fragmentos florestais de vegetação de Cerrado, Floresta Estacional Semidecidual e plantios comerciais de Eucalyptus grandis Hill Ex Maiden e Pinus caribaea var. hondurensis, em diferentes estágios de crescimento (Tabela 1). As condições edafoclimáticas e florísticas das áreas escolhidas são representativas das matas nativas e plantações florestais estabelecidos no planalto ocidental paulista (bacia hidrográfica do Rio Paraná). 
Tabela 1. Sítio, município, tipo de clima, tipo de solo e cobertura vegetal (tipo, idade, incremento médio anual de volume sólido de madeira com casca - i.m.a.) onde foram coletados os solos para os experimentos de incubação

\begin{tabular}{|c|c|c|c|c|c|c|c|}
\hline \multirow[t]{2}{*}{ Sítio } & \multirow[t]{2}{*}{ Município } & \multirow{2}{*}{$\begin{array}{l}\text { Tipo de } \\
\text { clima }^{1}\end{array}$} & \multirow{2}{*}{$\begin{array}{c}\text { Tipo } \\
\text { de solo }\end{array}$} & \multicolumn{3}{|c|}{ Cobertura vegetal } & \multirow{2}{*}{$\begin{array}{l}\text { Equipamento } \\
\text { preparo solo }\end{array}$} \\
\hline & & & & Tipo & Idade & I.M.A. & \\
\hline & & & & & ano & $\begin{array}{l}\mathrm{m}^{3} \mathbf{h a}^{-1} \\
\mathbf{a n o}^{-1}\end{array}$ & \\
\hline 1 & Agudos-SP & Cwa & $\mathrm{LV}^{4}$ & Püns coribaea var hontwersis & 0,3 & - & Subsolador \\
\hline 2 & Agudos-SP & Cwa & $\mathrm{LV}^{4}$ & Pöns coribara var honthersis & 20 & 35 & Grade pesada \\
\hline 3 & Agudos-SP & Cwa & $\mathrm{LV}^{3}$ & $\begin{array}{c}\text { Fragmento deSavana(floresta } \\
\text { estacional; Cerado) }\end{array}$ & - & - & - \\
\hline 4 & Ilbicatu-SP & Cwa & $\mathrm{PV}^{5}$ & $\begin{array}{l}\text { FragmentodeFloresta Estacional } \\
\text { Semidecidal, submantana }{ }^{2}\end{array}$ & - & - & - \\
\hline 5 & Ibicatu-SP & Cwa & $\mathrm{PV}^{5}$ & Cana-doapact & $\approx 1$ & $\begin{array}{l}50 \mathrm{tha}^{-1} \\
\text { ano }^{1}\end{array}$ & $\begin{array}{l}\text { Arado, grade } \\
\text { leve }\end{array}$ \\
\hline 6 & Luis Antônio-SP & Cwa & $\mathrm{LV}^{3}$ & $\begin{array}{l}\text { Fragmento de Savana (floresta } \\
\text { estacional; Carado) }\end{array}$ & - & - & - \\
\hline 7 & LuisAntônio-SP & Cwa & $\mathrm{LV}^{3}$ & Eucalyptus grandis & 3,4 & 23 & $\begin{array}{l}\text { Subsolador, } \\
\text { grade pesada }\end{array}$ \\
\hline 8 & Luis Antônio-SP & Cwa & $L^{3}$ & Eucalyptis grandis & 3,4 & 19 & Grade pesada \\
\hline 9 & Luis Amânio-SP & Cwa & $\mathrm{LV}^{3}$ & Eucalyptus grandis & 0,3 & - & Subsolador \\
\hline 10 & Itatinga-SP & Cwa & $\mathrm{LV}^{3}$ & Eucalyptrs gromdis & 7 & 30 & $\begin{array}{l}\text { Grade } \\
\text { "bedding" }\end{array}$ \\
\hline 11 & Itatinga-SP & Cwa & $\mathrm{LV}^{3}$ & $\begin{array}{l}\text { Eucalyptus grandis (área } \\
\text { refurmada) }\end{array}$ & 1 & 40 & Subsolador \\
\hline 12 & Butucatu-SP & Cwa & $\mathrm{LV}^{3}$ & $\begin{array}{l}\text { Fragmentode Savana(floresta } \\
\text { etacional; Centadăo) }\end{array}$ & - & - & - \\
\hline 13 & Botucatu-SP & Cwa & $\mathrm{LV}^{3}$ & Eucalyptus gromdis & 0,3 & - & Subsolador \\
\hline 14 & Botucatu-SP & Cwa & $\mathrm{LV}^{6}$ & Eucalyptos grandis & $15^{8}$ & 35 & $\begin{array}{l}\text { Grade } \\
\text { "bedding" }\end{array}$ \\
\hline 15 & Itarané-SP & Cfá & $\mathrm{LE}^{7}$ & Eucahptus grandis & 9 & 50 & Grade pesada \\
\hline 16 & Itararé-SP & Cfa & $\mathrm{LE}^{7}$ & $\begin{array}{l}\text { Fragmentode Floresta Estacional } \\
\text { Semidecidual, submontana }\end{array}$ & - & - & - \\
\hline
\end{tabular}

'Tipo de clima segundo a classificação de Köppen; ${ }^{2}$ Tipo de vegetação nativa conforme Mapa de Vegetação do Brasil (IBGE 1995, $2^{\mathrm{a}}$ impressão); ${ }^{3} \mathrm{LV}=$ latossolo vermelho-amarelo álico, textura média, relevo plano e suave ondulado; ${ }^{4} \mathrm{LV}=$ latossolo vermelho-amarelo distrófico, textura média, relevo plano e suave ondulado; ${ }^{5} \mathrm{PV}=$ podzólico vermelho-amarelo distrófico, textura arenosa/média, relevo ondulado e suave ondulado; ${ }^{6} \mathrm{LV}=$ latossolo vermelho-amarelo álico, textura argilosa, relevo suave ondulado e plano; ${ }^{7} \mathrm{LE}=$ latossolo vermelho-escuro álico, textura argilosa, relevo suave ondulado e plano; ${ }^{8}$ Povoamento manejado no sistema de talhadia, tendo sido realizado o primeiro corte raso aos 8 anos de idade, atualmente a brotação está com 7 anos de idade. 
Em cada fragmento florestal de mata nativa foi instalada uma parcela experimental com $900 \mathrm{~m}^{2}$ (30 x 30m). Nas áreas de eucalipto e pinus foram instaladas parcelas constituídas por 121 plantas, ou seja, 11 linhas com 11 árvores cada. Todas árvores das parcelas de eucalipto e pinus foram consideradas nas avaliações dendrométricas. Considerando uma área média de $7,5 \mathrm{~m}^{2}$ por árvore, cada parcela ocupava uma área média de aproximadamente $910 \mathrm{~m}^{2}$. Em todas parcelas experimentais (eucalipto e pinus) foram avaliados o crescimento em altura, em diâmetro à altura do peito (DAP), o fator de forma dos troncos e a sobrevivência das árvores. Com essas variáveis estimou-se o incremento médio anual de volume sólido de madeira com casca (I.M.A.) de cada sítio florestal (Tabela 1).

\subsection{Caracterização química e física do solo}

As características químicas e fisicas do solo foram determinadas para as camadas de 0-5 e 5-15 cm de profundidade para todos os sítios onde foram realizados os estudos de mineralização de $\mathrm{N}$.

As determinações granulométricas, densidade do solo e densidade de partículas foram realizadas segundo a metodologia apresentada pela EMBRAPA (1997). As determinações de $\mathrm{pH}$, carbono orgânico, fósforo disponível, cálcio, magnésio, potássio, alumínio trocável, acidez potencial, hidrogênio titulável, capacidade de troca de çations, saturação de bases e alumínio foram feitas segundo Raij et al. (1977).

As características químicas e fisicas do solo determinadas para a camada de 0-15 cm de profundidade para todos os sítios são apresentadas na Tabela 2. 


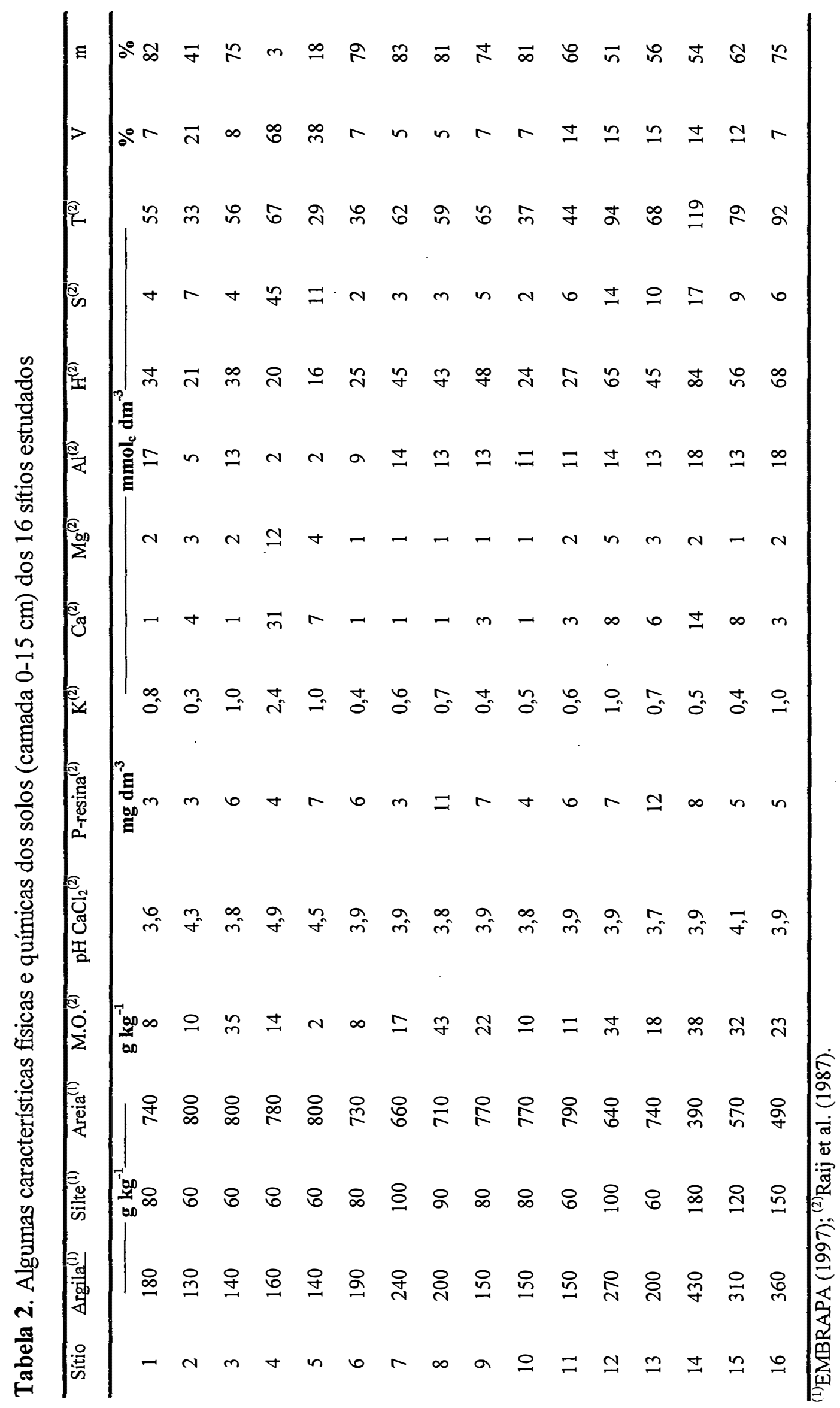




\subsection{Mineralização de nitrogênio sob condições de laboratório}

De todos sítios florestais (Tabela 1), foram realizadas amostragens de solo das camadas 0-5 e 5-15 cm para as avaliações das taxas de mineralização de $\mathrm{N}$ sob condições de laboratório (incubação aeróbica e anaeróbica). Vinte amostras simples de cada camada compuseram uma amostra composta, a qual foi seca à sombra, homogeneizada e peneirada $(2 \mathrm{~mm})$.

3.3.1 Mineralização aeróbica de nitrogênio (conforme metodologia de Stanford \& Smith, 1972)

Para a incubação aeróbica do solo foram usados funis de polietileno com capacidade para $250 \mathrm{~g}$ de solo. Na parte inferior do funil, foi colocado uma bucha de lã de vidro com a finalidade de reter o solo. Em cada funil foi incubado $60 \mathrm{~g}$ de solo misturado com $8 \mathrm{~g}$ de vermiculita (partículas entre 0,8 e $0,4 \mathrm{~mm}$ de diâmetro). Sobre a mistura solo-vermiculita foi colocada uma camada de lã de vidro, para evitar a dispersão do solo ao adicionar-se a solução extratora.

A extração do $\mathrm{N}$ mineralizado foi realizada percolando-se o solo com 200 $\mathrm{ml} \mathrm{de} \mathrm{CaCl}_{2} \quad 0,01 \mathrm{~mol} \mathrm{~L}^{-1}$, adicionando-se a seguir $50 \mathrm{ml}$ de solução nutritiva, constituída de $\mathrm{K}_{2} \mathrm{SO}_{4}\left(0,0025 \mathrm{~mol} \mathrm{~L}^{-1}\right), \mathrm{MgSO}_{4}\left(0,002 \mathrm{~mol} \mathrm{~L}^{-1}\right)$ e $\mathrm{Ca}\left(\mathrm{H}_{2} \mathrm{SO}_{4}\right)_{2}\left(0,005 \mathrm{~mol} \mathrm{~L}^{-1}\right)$. Não foi necessário retirar o excesso de solução com uma bomba de vácuo, porque todas amostras de solo apresentaram boa drenagem; esta etapa é fundamental pra solos com mineralogia predominantemente caulinítica e de argilas 2:1. Os funis foram cobertos com um filme de polietileno para evitar perdas de água por evaporação e incubados à uma temperatura constantel de $20^{\circ} \mathrm{C} \pm 1^{\circ} \mathrm{C}$. 
Após a extração inicial do $\mathrm{N}$, os solos foram incubados por períodos sucessivos de $3,6,10,14,20$ e 30 semanas. Após cada período de incubação foram realizadas as mesmas operações descritas anteriormente.

As determinações das concentrações de $\mathrm{N}-\mathrm{NH}_{4}{ }^{+}$e $\mathrm{N}-\mathrm{NO}_{3}{ }^{-}$mineralizados nos extratos foram realizadas com o emprego do Sistema de Análise em Fluxo - FIA (Ruzicka \& Hansen, 1975). $\mathrm{O} \mathrm{N}-\mathrm{NH}_{4}{ }^{+}$foi determinado pelo método condutivimétrico e o $\mathrm{N}-\mathrm{NO}_{3}{ }^{-}$pelo método colorimétrico, sendo os limites de deteç̧ão obtidos de 0,25 e 0,05 $\mu \mathrm{g} \mathrm{mL}^{-1}$, respectivamente. Para a obtenção das concentrações de $\mathrm{N}-\mathrm{NH}_{4}{ }^{+}$e N-NO${ }_{3}^{-}$no solo, cada concentração obtida pelo sistema FIA foi multiplicado pelo volume de extrato e dividida pela massa de terra seca da amostra. Portanto, as concentrações de $\mathrm{N}^{-\mathrm{NH}_{4}}{ }^{+}$e $\mathrm{N}-\mathrm{NO}_{3}{ }^{-}$no solo foram expressas em $\mathrm{mg} \mathrm{kg}^{-1}$ de terra seca. A densidade do solo foi utilizada para converter as concentrações de $\mathrm{N}$ mineral do solo em conteúdo por área $(\mathrm{kg}$ $\left.\mathrm{ha}^{-1}\right)$.

3.3.2 Mineralização anaeróbica de $\mathbf{N}$ (conforme metodologia de Waring \& Bremmer, 1964)

Para a extração inicial de $\mathrm{N}$ no experimento de incubação anaeróbica foram colocados $10 \mathrm{~g}$ de solo seco $(<2 \mathrm{~mm})$ em tubos de centrífuga de $50 \mathrm{ml}$. A seguir foi adicionado $30 \mathrm{ml}$ de $\mathrm{KCl} 2 \mathrm{~mol} \mathrm{~L}^{-1}$, os tubos foram agitados por 45 minutos e centrifugados a $2.000 \mathrm{rpm}$, durante 15 minutos. Depois, as quantidades iniciais de N$\mathrm{NH}_{4}{ }^{+}$e N-NO${ }_{3}^{-}$foram determinadas, conforme metodologia descrita anteriormente.

Para as incubações, foram acrescentados, nesses tubos de centrífuga, 30 $\mathrm{ml}$ de solução nutritiva constituída de: $\mathrm{MgSO}_{4}\left(0,002 \mathrm{~mol} \mathrm{~L}^{-1}\right)$ e $\mathrm{Ca}\left(\mathrm{H}_{2} \mathrm{PO}_{4}\right)_{2}(0,005 \mathrm{~mol}$ $\left.\mathrm{L}^{-1}\right)$. Os tubos foram agitados manualmente até a dispersão dos solos e depois tampados 
com papel de alumínio, para prevenir perdas d'água por evaporação e crescimento de algas.

A primeira extração de $\mathrm{N}$ foi realizada três semanas após o inicio da incubação, adicionando-se 5,2 g de $\mathrm{KCl}$ (sal anidro) a cada tubo de centrífuga, para obter uma concentração de $2 \mathrm{~mol} \mathrm{~L}^{-1}$ de $\mathrm{KCl}$. Os tubos foram agitados e centrifugados da mesma forma feita para a extração do $\mathrm{N}$ presente antes da incubação. Estas operações já foram realizadas após 3, 6, 10, 14, 20 e 30 semanas de incubação.

Tanto as incubações aeróbicas como as anaeróbicas foram realizadas usando o delineamento experimental do tipo inteiramente casualizado, com três repetições.

\subsection{Análise estatística e interpretação dos dados}

A cinética de mineralização de $\mathrm{N}, \mathrm{o}$ potencialmente mineralizável $\left(\mathrm{N}_{0}\right)$ e a constante de mineralização de $\mathrm{N}(\mathrm{k})$ foram modelados e estimados por uma equação exponencial recomendada por Stanford \& Smith (1972). Estes pesquisadores, partindo da premissa de que apenas uma fração do $\mathrm{N}$ total do solo é potencialmente mineralizável, propuseram que o processo de mineralização de $\mathrm{N}$ segue uma cinética de primeira ordem, $\mathrm{dN} / \mathrm{dt}=-\mathrm{kN}$, onde $\mathrm{N}$ é igual a $\mathrm{N}_{0}-\mathrm{N}_{\mathrm{t}} ; \mathrm{N}_{0}$ é igual ao $\mathrm{N}$ potencialmente mineralizável (mg $\mathrm{kg}^{-1}$ de solo); $\mathrm{N}_{\mathrm{t}}$ é igual ao $\mathrm{N}$ mineralizado acumulado até o tempo t (semanas); e k é igual a constante de mineralização de $\mathrm{N}\left(\right.$ semana $\left.^{-1}\right)$. Integrando esta expressão se obtém a seguinte equação linear:

$$
\log \left(\mathrm{N}_{0}-\mathrm{N}_{\mathrm{t}}\right)=\log \mathrm{N}_{0}-\mathrm{kt} / 2,303 \text {, cuja forma exponencial é } \mathrm{N}_{\mathrm{t}}=\mathrm{N}_{0}\left(1-\mathrm{e}^{-\mathrm{kt}}\right) \text {. }
$$


Conforme recomendação destes pesquisadores, antes de ajustar essa equação aos dados, o primeiro passo foi estimar $N_{0}$ pela equação: $1 / N_{t}=1 / N_{0}+b / t$, onde b é uma simples constante. Nesta estimativa, foi eliminado a quantidade de $\mathrm{N}$ obtida no $\mathrm{t}_{0}$, por ter sido mineralizado antes da incubação das amostras de solo. Após este passo, estimou-se $k$ pela equação $\log \left(\mathrm{N}_{0}-\mathrm{N}_{\mathrm{t}}\right)=\log \mathrm{N}_{0}-\mathrm{kt} / 2,303$. $\mathrm{O}$ valor de $\mathrm{N}_{0}$ estimado nesta equação não é necessariamente igual ao $\mathrm{N}_{0}$ estimado anteriormente.

Para descrever a cinética de mineralização de $\mathrm{N}$ e estimar $\mathrm{N}_{0}$, foi usado também a equação: $\mathrm{N}_{\mathrm{t}}=\mathrm{a}+\mathrm{b} / \mathrm{t}$, onde $\mathrm{N}_{\mathrm{t}}$ é o $\mathrm{N}$ mineralizado $\left(\mathrm{mg} \mathrm{kg}^{-1}\right.$ de solo), acumulado até o tempo $t$ (semanas). Observa-se que nesta equação quando $t$ tende para $o$ $\infty$, a relação b/t tende para 0 , por conseguinte a é o valor máximo de $\mathrm{N}_{t}$, ou seja $\mathrm{N}_{0}$. Desta forma, a equação pode ser apresentada como: $\mathrm{N}_{\mathrm{t}}^{\prime}=\mathrm{N}_{0}+\mathrm{b} / \mathrm{t}$. 


\section{RESULTADOS E DISCUSSÃO}

\subsection{Cinética de mineralização e estimativa do nitrogênio potencialmente mineralizável}

A mineralização acumulada de $\mathrm{N}$, em condições aeróbicas e anaeróbicas, mostrou uma relação exponencial com o tempo de incubação. A equação $N_{t}=N_{0}+b / t$ ajustou-se melhor aos dados do que a equação proposta por Stanford \& Smith (1972), $\mathrm{N}_{\mathrm{t}}$ $=\mathrm{N}_{0}\left(1-\mathrm{e}^{-\mathrm{kt}}\right)$ (Figuras 1, 2 e 3); embora os coeficientes de determinação, para ambas equações, serem superiores a 90\% ( $\mathrm{p}<0,01)$. A equação proposta por Stanford \& Smith (1972) superestimou os valores de $\mathrm{N}_{0}$ em vários sítios e condições de incubação (Tabela 3), além de não modelar-se adequadamente aos dados, como fica evidente na figura 3 , que compara o ajuste dessas duas equações aos dados. Essa superestimação também foi verificada por Cabrera (1993). Projetando-se, imaginariamente, os dados observados de mineralização de $\mathrm{N}$ a valores bem elevados de tempo de incubação, constata-se que o somatório dos resíduos entre valores observados e estimados pela equação de Stanford \& Smith (1972) dão valores baixos, daí a explicação para os altos coeficientes de determinação encontrados por essas equações, apesar de não serem adequadamente ajustadas aos dados (Figura 3). Por todas essas razões, sugere-se o uso da equação $N_{t}=$ $\mathrm{N}_{0}+\mathrm{b} / \mathrm{t}$ para modelar a cinética de mineralização de $\mathrm{N}$. Para a estimativa de $\mathrm{N}_{0}$ por meio desta equação, recomenda-se usar um $\mathbf{t}$ igual a 20 semanas a uma temperatura de incubação média de $20^{\circ} \mathrm{C}$; menor período será necessário para temperaturas maiores (recomenda-se no máximo $28^{\circ} \mathrm{C}$ ). No presente estudo, as taxas de mineralização de $\mathrm{N}$ estabilizaram após 8 a 15 semanas de incubação. Nestes períodos, deve ter ocorrido, predominantemente, a mineralização de formas mais lábeis de $\mathrm{N}$ orgânico. 
Tabela 3. Teor de matéria orgânica (M.O.), C total $\left(C_{t}\right), N$ total $\left(N_{t}\right), N$ mineralizado em 30 semanas a $20^{\circ} \mathrm{C}\left(\mathrm{N}_{\mathrm{m}}\right)$, N potencialmente mineralizável $\left(\mathrm{N}_{0}\right)$ e constante de mineralização de $N$ (k) da camada 0-15 cm dos solos amostrados nos diversos sítios florestais

\begin{tabular}{|c|c|c|c|c|c|c|c|c|}
\hline \multirow[t]{2}{*}{ Sítio } & $\begin{array}{l}\text { M.O. } \\
\text { g kg }^{-1}\end{array}$ & $\mathbf{C}_{\mathbf{t}}$ & $\mathbf{N}_{t}^{(1)}$ & $\frac{N_{m}}{m^{\prime g ~ k g}}$ & $\mathbf{N}_{0}^{(2)}$ & $\mathrm{N}_{0}^{(3)}$ & $\begin{array}{c}\mathbf{N}_{\mathbf{0}} / \mathbf{N}_{t}^{(4)} \\
\%\end{array}$ & stmara \\
\hline & \multicolumn{3}{|l|}{$\mathrm{g} \mathrm{kg}^{-1}$} & & \multicolumn{4}{|c|}{ Incubação aeróbica } \\
\hline 1 & 8 & 4507 & 451 & 36 & 46 & 39 & 9 & 0,032 \\
\hline 2 & 10 & 5562 & 556 & 28 & 35 & 30 & 5 & 0,035 \\
\hline 3 & 35 & 20093 & 2009 & 59 & 76 & 65 & 3 & 0,029 \\
\hline 4 & 14 & 7972 & 797 & 31 & 69 & 35 & 4 & 0,015 \\
\hline 5 & 2 & 1383 & 138 & 10 & 15 & 12 & 9 & 0,026 \\
\hline 6 & 8 & 4849 & 485 & 21 & 26 & 23 & 5 & 0,032 \\
\hline 7 & 17 & 9764 & 976 & 25 & 34 & 26 & 3 & 0,033 \\
\hline 8 & 43 & 24781 & 2478 & 30 & 44 & 32 & 1 & 0,030 \\
\hline 9 & 22 & 12835 & 1284 & 20 & 29 & 21 & 2 & 0,033 \\
\hline 10 & 10 & 5533 & 553 & 28 & 38 & 31 & . 6 & 0,029 \\
\hline 11 & 11 & 6247 & 625 & 30 & 41 & 33 & 5 & 0,029 \\
\hline 12 & 34 & 19899 & 1990 & 85 & 122 & 89 & 4 & 0,033 \\
\hline 13 & 18 & 10151 & 1015 & 45 & 53 & 48 & 5 & 0,041 \\
\hline 14 & 38 & 21784 & 2178 & 81 & 111 & 83 & 4 & 0,034 \\
\hline 15 & 32 & 18787 & 1879 & 56 & 68 & 60 & 3 & 0,038 \\
\hline 16 & 23 & 13518 & 1352 & 53 & 83 & 57 & 4 & 0,027 \\
\hline Média & 20 & 11729 & 1173 & 40 & 56 & 43 & 4 & 0,031 \\
\hline \multirow[t]{2}{*}{ $\pm s$} & 13 & 7284 & 728 & 22 & 30 & 22 & 3 & 0,006 \\
\hline & & & & \multicolumn{5}{|c|}{ - Incubação anaeróbica - } \\
\hline 1 & 8 & 4507 & 451 & 43 & 57 & 44 & 10 & 0,040 \\
\hline 2 & 10 & 5562 & 556 & 44 & 50 & 45 & 8 & 0,052 \\
\hline 3 & 35 & 20093 & 2009 & 167 & 343 & 173 & 9 & 0,018 \\
\hline 4 & 14 & 7972 & 797 & 106 & 120 & 107 & 13 & 0,057 \\
\hline 5 & 2 & 1383 & 138 & 77 & 149 & 86 & 62 & 0,017 \\
\hline 6 & 8 & 4849 & 485 & 39 & 46 & 40 & 8 & 0,049 \\
\hline 7 & 17 & 9764 & 976 & 105 & 150 & 110 & 11 & 0,032 \\
\hline 8 & 43 & 24781 & 2478 & 107 & 151 & 113 & 5 & 0,032 \\
\hline 9 & 22 & 12835 & 1284 & 73 & 103 & 76 & 6 & 0,033 \\
\hline 10 & 10 & 5533 & 553 & 50 & 69 & 53 & 10 & 0,034 \\
\hline 11 & 11 & 6247 & 625 & 63 & 86 & 66 & 11 & 0,033 \\
\hline 12 & 34 & 19899 & 1990 & 269 & 465 & 269 & 14 & 0,026 \\
\hline 13 & 18 & 10151 & 1015 & 75 & 87 & 75 & 7 & 0,056 \\
\hline 14 & 38 & 21784 & 2178 & 249 & 392 & 244 & 11 & 0,030 \\
\hline 15 & 32 & 18787 & 1879 & 164 & 249 & 166 & 9 & 0,031 \\
\hline 16 & 23 & 13518 & 1352 & 214 & 345 & 205 & 15 & 0,030 \\
\hline Média & 20 & 11729 & 1173 & 115 & 179 & 117 & 10 & 0,036 \\
\hline$\pm \mathbf{s}$ & 13 & 7284 & 728 & 75 & 136 & 73 & 10 & 0,012 \\
\hline
\end{tabular}

(1) $\mathrm{N}$ total estimado considerando-se uma relação média $\mathrm{C}$ total: $\mathrm{N}$ total $=10: 1$, obtida por Kiehl (1979), para os mesmos solos no estado de São Paulo $;{ }^{(2)} \mathrm{N}$ potencialmente mineralizável e constante de mineralização de $\mathrm{N}$ estimados pela equação de Stanford \& Smith (1972); ${ }^{(3)} \mathrm{N}$ potencialmente mineralizável estimado pela equação: $N_{t}=N_{0}+b / t$; e ${ }^{(4)} \mathrm{N}$ potencialmente mineralizável estimado por esta equação dividido por $\mathrm{N}_{\mathrm{t}}$ vezes 100. 


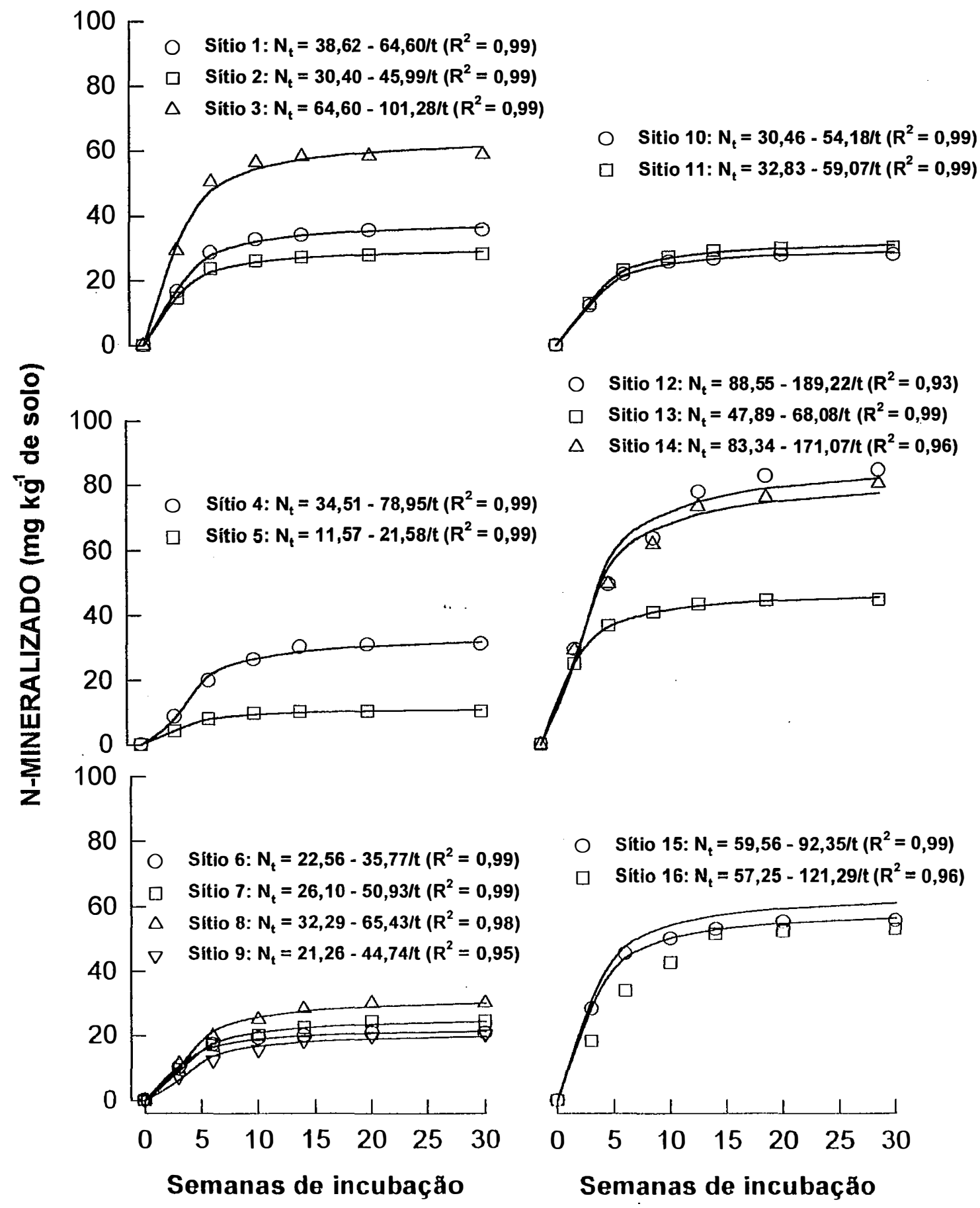

Figura 1. Curvas de mincralização acróbica de $\mathrm{N}$ para a camada $0-15 \mathrm{~cm}$ dos solos amostrados nos diversos sítios llorestais. Todos valores dos coclicientes de 


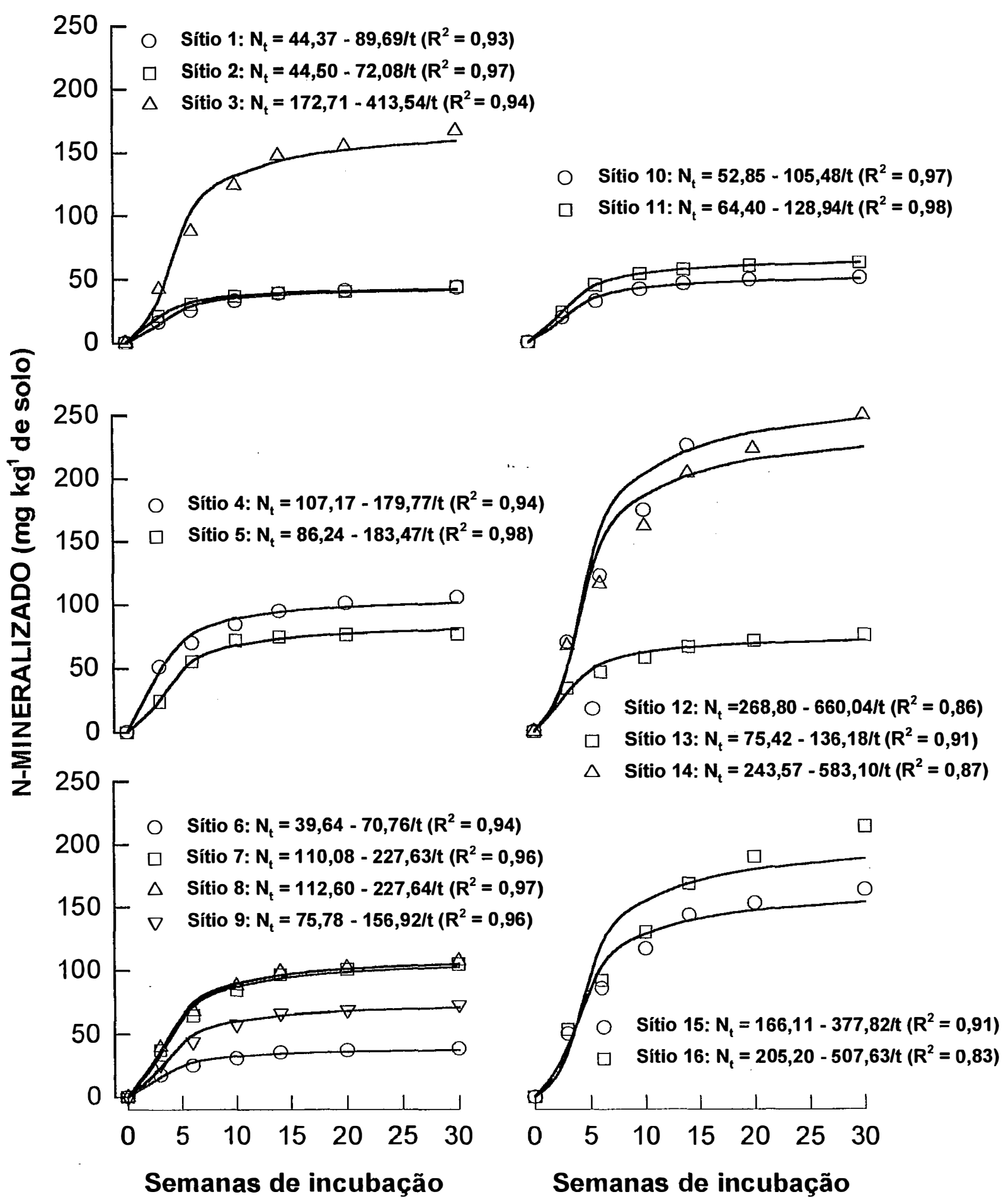

Figura 2. Curvas de mineralização anaeróbica de $\mathrm{N}$ para a camada $0-15 \mathrm{~cm}$ dos solos amostrados nos diversos sítios florestais. Todos valores dos coclicientes de determinação são significantes a um nível de probabilidade menor que $1 \%$. 


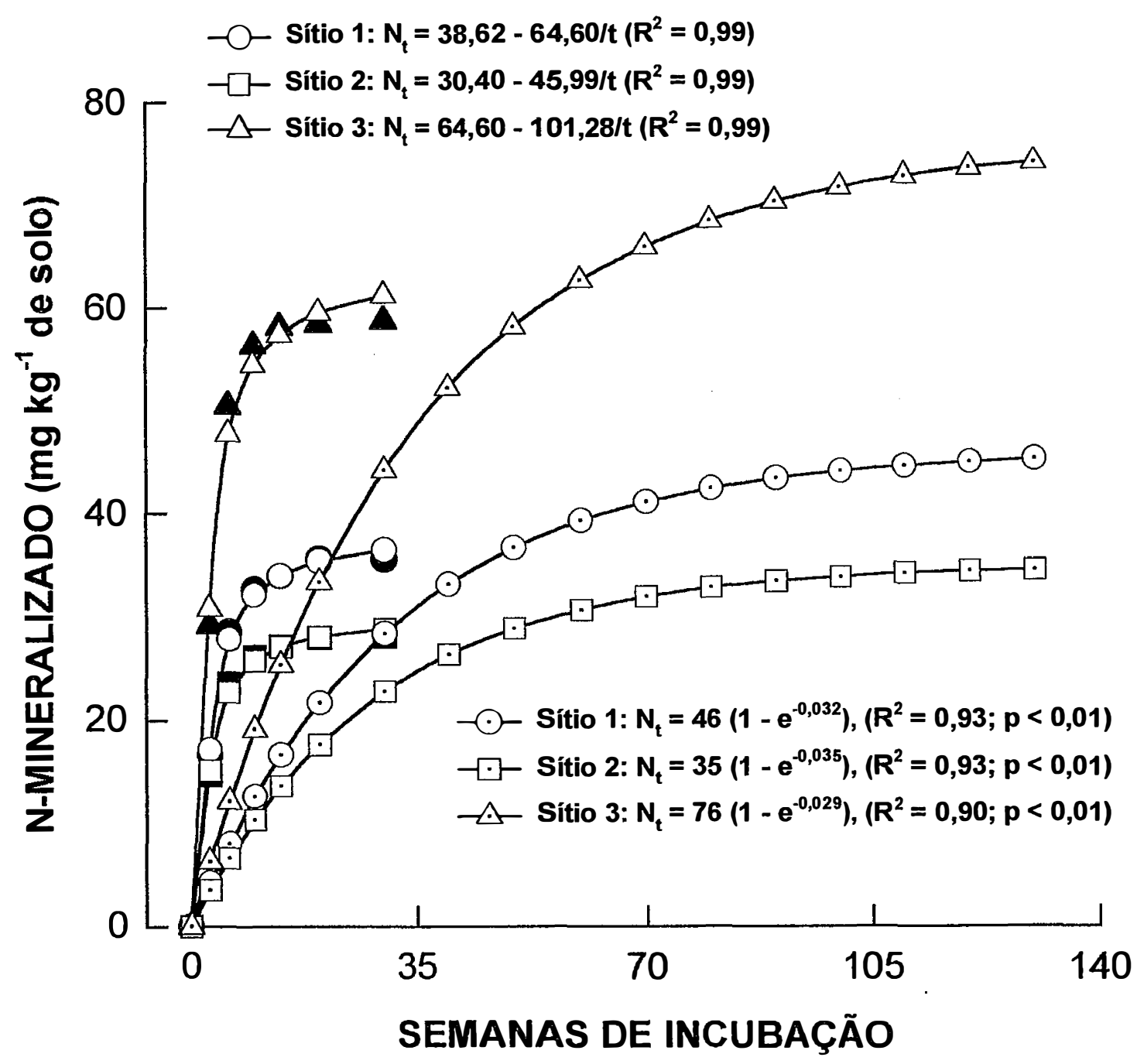

Figura 3. Dados experimentais de mineralização aeróbica de $\mathrm{N}$ dos sítios florestais 1 , 2 e 3 , e valores estimados pela equação $N_{1}=N_{0}\left(1-\mathrm{e}^{-k}\right)$, proposta por Stanford \& Smith (1972), comparativamente aos estimados pela equação $\mathrm{N}_{\mathrm{t}}$ $=\mathrm{N}_{0}-\mathrm{b} / \mathrm{t}$. 
As quantidades de $\mathrm{N}_{0}$, sob condições aeróbicas, estimados pela equação $\mathrm{N}_{t}$ $=\mathrm{N}_{0}+\mathrm{b} / \mathrm{t}$, variaram entre 12 a $89 \mathrm{mg} \mathrm{kg}^{-1}$ de solo $\left(36\right.$ a $214 \mathrm{~kg} \mathrm{ha}^{-1}$; considerando uma camada de 0-20 cm de solo e densidade do solo $=1,2$ ), com média de $43 \pm 22 \mathrm{mg} \mathrm{kg}^{-1} \mathrm{de}$ solo $\left(103 \pm 53 \mathrm{~kg} \mathrm{ha}^{-1}\right)$. Sob condições anaeróbicas, os valores de $\mathrm{N}_{0}$ variaram entre $40 \mathrm{a}$ $269 \mathrm{mg} \mathrm{kg}^{-1}$ de solo (96 a $\left.646 \mathrm{~kg} \mathrm{ha}^{-1}\right)$, com média de $117 \pm 73 \mathrm{mg} \mathrm{kg}^{-1}$ de solo $(281 \pm$ $175 \mathrm{~kg} \mathrm{ha}^{-1}$ ) (Tabela 3). Observa-se que os valores de $\mathrm{N}_{0}$ obtidos sob condições anaeróbicas foram, em média, 2,7 vezes maiores do que aqueles obtidos sob condições aeróbicas. Tomando-se por base que as estimativas de $\mathrm{N}_{0}$ nos dois métodos foram realizadas por meios biológicos, que espécies de Eucalyptus plantadas em solos semelhantes ao do presente estudo assimilam em sua biomassa aérea e radicular quantidades de $\mathrm{N}$ que variam comumente de 300 a $700 \mathrm{~kg} \mathrm{ha}^{-1}$ (idade de 6 a 8 anos) e que as maiores reservas de $\mathrm{N}$ estão na camada $0-20 \mathrm{~cm}$ de solo (Gonçalves et al. 1997b e Salcedo et al. 1985), admite-se que os valores de $\mathrm{N}_{0}$ obtidos aerobicamente estão subestimados. Várias razões podem ser apontadas, como, por exemplo, (i) os potenciais efeitos nocivos da lixiviação periódica do solo com solução salina $\left(\mathrm{CaCl}_{2} 0,01 \mathrm{~mol} \mathrm{~L}^{-1}\right)$ sobre a atividade das comunidades microbianas dos solos (Keeney 1982) e (ii) a remoção, com as lixiviações, de grande quantidade de N-orgânico solúvel, potencialmente mineralizável. Gianello et al. (1995), trabalhando com dez solos representativos do Rio Grande do Sul, verificaram que, em média, 37\% do N-total lixiviado após 32 semanas de incubação aeróbica estava em formas orgânicas solúveis. A despeito das evidências de que as quantidades de $\mathrm{N}$ mineralizadas aerobicamente foram subestimadas, encontrou-se alta correlação entre os valores de $N_{0}$ obtidos aeróbia e anacrobicamente, $r=0,87(n=$ $16 ; \mathrm{p}=0,05$ ); alćm disso, em ambos métodos a cinćtica de mincralização de $\mathrm{N}$ se ajustaram bem a um mesmo modelo de regressão (liiguras l c 2). Isto constituem evidências de que os processos de mineralização de $\mathrm{N}$ são semelhantes, distinto apenas nos indices de mincralizaçato, provavelnente pela presença de mais lattores limitantes yuando usado o método acróbico. 
As razões entre as percentagens de $\mathrm{N}_{0}$, estimados em condições anaeróbias, e ao $\mathrm{N}_{\mathrm{t}}(\mathrm{N}$-total) variaram, na sua grande maioria, entre 5 a $15 \%$, maiores do que as estimadas em condições aeróbicas 3 a 9\% (Tabela 3). Tomando-se por base essas razões, deduz-se que apenas 5 a 15\% do teor de matéria orgânica do solo, principal fonte de $\mathrm{N}$ para as árvores, é decomponível. Esta variação dependeu da qualidade do sítio, principalmente aquelas relacionadas com o teor e qualidade da matéria orgânica do solo (MOS) e sua textura.

Os teores argila, de MOS, de $\mathrm{N}$ total, de $\mathrm{H}^{0}$ e $\mathrm{T}$ foram significativamente correlacionados com os valores de $\mathrm{N}_{0}$ (estimado pela equação $\mathrm{N}_{\mathrm{t}}=\mathrm{N}_{0}+\mathrm{b} / \mathrm{t}$ ), em ambas condições de drenagem, sendo iguais a 0,76 , a 0,75 , a 0,75 , a 0,82 e a 0,85 , respectivamente, todos com $\mathrm{p}<0,01$, quando $\mathrm{N}_{0}$ foi obtido em condições anaeróbicas. $\mathrm{N}_{0}$ não correlacionou-se significativamente com as demais características químicas do solo. Observa-se que $\mathrm{N}_{0}$ só correlacionou-se significativamente com as características normalmente relacionadas com o teor de $\mathrm{N}$ orgânico do solo.

Considerando-se apenas a exportação média de $\mathrm{N}$ em vários povoamentos de E. grandis (via madeira descascada) no estado de São Paulo, igual a $120 \mathrm{~kg} \mathrm{ha}^{-1}$ rotação $^{-1}$ (Gonçalves, 1995), constata-se que os estoques de $\mathrm{N}$ da camada de solo (0-20 cm) são suficientes apenas para 2 a 3 rotações de cultivo ( 7 anos cada). Adicionalmente, admitindo-se que em camadas de solo inferiores a 0-20 cm também seja absorvido certa quantidade de $\mathrm{N}$ (bem inferior à camada superior), que sejam realizadas adubações nitrogenada equivalentes a 50-60 $\mathrm{kg} \mathrm{ha}^{-1}$ rotação $^{-1}$ (cerca de 40 a $50 \%$ dc aproveitamento pelas árvores) e que, por meio das chuvas, sejam depositados cerca de 8-10 $\mathrm{kg} \mathrm{ha}^{-1} \mathrm{ano}^{-1}$ de $\mathrm{N}$, acredita-se que os estoques de $\mathrm{N}$ sejam suficientes para mais 1 a 1,5 rotações de cultivo. Portanto, estima-se que as reservas médias de $\mathrm{N}$ dos sítios pesquisados sejam sulicientes para 3 a 5 rotaçóes de cultivo de li. grandis. No lim deste período, é prováivel cue as respostas à adubação nitrogenada scjam bastante signilicativas. 
Por todas estas vantagens, o método de mineralização anaeróbica de $\mathrm{N}$ é $\mathrm{o}$ mais recomendado, em análises laboratoriais de rotina, para a determinação da cinética de mineralização de $\mathrm{N}$ e estimativa de $\mathrm{N}_{0}$. A curva de mineralização de $\mathrm{N}$ e o valor de $\mathrm{N}_{0}$ podem ser satisfatoriamente estimados em sucessivos períodos de incubação de 2 semanas num período de tempo total igual a 8 semanas, ao invés de 30 semanas, a uma temperatura de equilibrio maior do que $20^{\circ} \mathrm{C}$ (como por exemplo $28^{\circ} \mathrm{C}$ ).

\subsection{Efeito da cobertura vegetal sobre as formas e as quantidades de nitrogênio potencialmente mineralizável}

Em alguns sítios, a presença da mata nativa redundou em maiores quantidades de $\mathrm{N}$ potencialmente mineralizável $\left(\mathrm{N}_{0}\right)$. Por exemplo, o $\mathrm{N}_{0}$ estimado para $\mathrm{o}$ sítio 3 (fragmento de Cerrado), em condições anaeróbicas, $173 \mathrm{mg} \mathrm{de} \mathrm{N} \mathrm{kg}^{-1}$ de solo, foi superior ao do sítio 1 (florestamento de Pinus caribaea var. hondurensis, recém

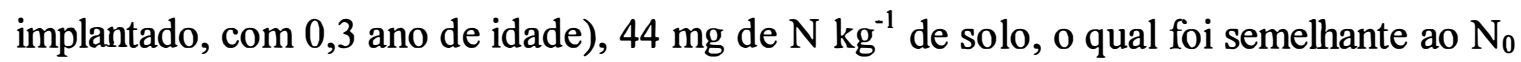
obtido no sítio 2 (florestamento de Pinus caribaea var. hondurensis, com 20 anos de

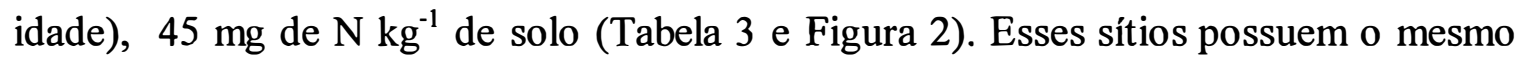
tipo de solo (Tabela 1), e características granulométricas e químicas próximas entre si (Tabela 2). $\mathrm{O}$ maior $\mathrm{N}_{0}$ obtido no sítio 3 , provavelmente se deve ao maior acúmulo de

MOS, $35 \mathrm{~g} \mathrm{~kg}^{-1}$ de solo, comparativamente a 10 e $8 \mathrm{~g} \mathrm{~kg}^{-1}$ de solo, respectivamente, para os sítios 2 e 1 (Tabela 3). O maior acúmulo de matéria orgânica do solo (MOS) desse sítio deve ter sido proporcionado pela maior produção líquida de matéria orgânica proveniente da decomposição de raízes, principalmente as finas, e incorporação ao solo de parte da serapilheira, pela atividade da fauna do solo. Coerentemente, no sítio 3, também foi encontrado maior quantidade de $\mathrm{N}$ total $\left(\mathrm{N}_{\mathrm{t}}\right)$ e maior razão $\mathrm{N}_{0}: \mathrm{N}_{\mathrm{t}}$ (Tabela 3). Esta é uma evidência clara de que as formas de $\mathrm{N}$ contidas na MOS do sítio 3 devem ser mais decomponíveis, provavelmente devido a maiores teores de amino ácidos, ácidos núcleicos e hexoaminas, compostos mais comuns em florestas nativas de folhas largas 
(com grande diversidade de espécies,.. inclusive leguminosas) relativamente a povoamentos homogêneos de Pinus.

Os sítios 4 (fragmento de Floresta Estacional Semidecidual, submontana) e 5 (área usada a vários anos com cultivo agrícola, atualmente com plantação de cana-deaçúcar), próximos entre si, apresentaram $\mathrm{N}_{0}$ completamente distintos, 107 e $86 \mathrm{mg} \mathrm{kg}^{-1}$ de solo, respectivamente (Tabela 3 e Figura 2). Grandes diferenças também foram observadas para o nível de fertilidade do solo (camada 0-15 cm); o sítio 4 apresenta-se mais fértil, com nível de $\operatorname{MOS}$ e de $\mathrm{N}_{\mathrm{t}}$ muito superior ao do sítio 5 (Tabela 2). Aqui fica bem caracterizado o efeito depressivo de vários ciclos de cultivo agrícola sobre os níveis de MOS e nutrientes disponíveis, causado por perdas como erosão, lixiviação, volatilização e, exportação de nutrientes pela colheita maior do que a reposição via adubação. Efeitos semelhantes tem sido retratado por vários pesquisadores (Carlyle et al. 1990).

Nos sítios 12 (fragmento de Cerradão) e 14 (florestado com Eucalyptus grandis a 15 anos), as quantidades de $\mathrm{N}_{0}$ foram muito superiores a do sítio 13 (florestado com Eucalyptus grandis, recém reformado, a 0,3 ano) (Figura 2 e Tabela 3). Esses resultados destacam o grande efeito de florestas adultas sobre os estoques de $\mathrm{N}_{0}$, principalmente devido as grandes quantidades de $\mathrm{N}$ cicladas biogeoquimicamente. Observar que a floresta adulta de eucalipto foi capaz de manter no solo níveis de $\mathrm{N}_{0}$ similares ao da floresta nativa, típica da área, e que, houve uma depleção muito grande da quantidade de $\mathrm{N}_{0}$ com o corte raso da floresta, ocorrido poucos meses antes (cerca de seis meses). O mesmo efeito não foi observado nos sítios com povoamento de Pinus (sítios 1 e 2) relativamente ao fragmento de mata nativa localizado ao lado (sítio 3), como já discutido. Provavelmente, em função das maiores quantidades de $\mathrm{N}$ cicladas biogeoquimicamente em plantações de Eucalyptus (Reis et al. 1990), assim como devido às menores taxas de decomposição de resíduos vegetais de Pinus (Poggiani 1985). 
Valores semelhantes de $\mathrm{N}_{0}$ para plantações de Eucalyptus e mata nativa do tipo 'Cerrado' também foram observadas entre os sítios 15 e 16 e, sítios 6 a 9 (Tabela 3).

Sob condições aeróbicas, a razão média $\mathrm{N}_{-} \mathrm{NH}_{4}{ }^{+}: \mathrm{N}^{-} \mathrm{NO}_{3}{ }^{-}$, quando se considera a média de todos os sítios foi igual a 3,6 $\pm 1,8$; sob condições anaeróbicas não foi encontrado $\mathrm{N}^{-\mathrm{NO}_{3}}{ }^{-}$(Tabelas 4 e 5). A predominância de $\mathrm{N}-\mathrm{NH}_{4}{ }^{+}$em solos sob florestas, assim como a absorção desta fonte de $\mathrm{N}$, também foram verificadas por Smethurst et al. (1990), Gonçalves \& Carlỵle (1994), Serrano (1997), Gonçalves et al. 1997b. A magnitude do processo de nitrificação em povoamentos florestais é pequena em relação àquele verificado na maioria das áreas usadas para fins agrícolas, devido a grande absorção de $\mathrm{NH}_{4}{ }^{+}$pelas árvores - substrato das bactérias nitrificadoras -, e das condições adversas dos vários solos usados para fins florestais, tais como a baixa fertilidade natural e elevada acidez. Na maioria dos solos usados para fins florestais, a demanda por $\mathrm{N}$ pelos organismos heterotróficos (espécies arbóreas, herbáceas e microorganismos) é tão grande, em resposta à disponibilidade de $\mathrm{C}$, que sobra pouco $\mathrm{NH}_{4}{ }^{+}$dos processos de mineralização da matéria orgânica para serem nitrificados (Jansson 1958; Paul \& Juna 1981 e Attiwill \& Lepper 1987). A maior parte do $\mathrm{NH}_{4}{ }^{+}$é absorvida ou imobilizada. Os únicos solos que apresentaram razão média $\mathrm{N}-\mathrm{NH}_{4}{ }^{+}: \mathrm{N}^{-} \mathrm{NO}_{3}{ }^{-}$inferior a 1 foram os dos sítios 4 e 5, que apresentaram saturações por bases e níveis de $\mathrm{pH}$ mais elevados. 


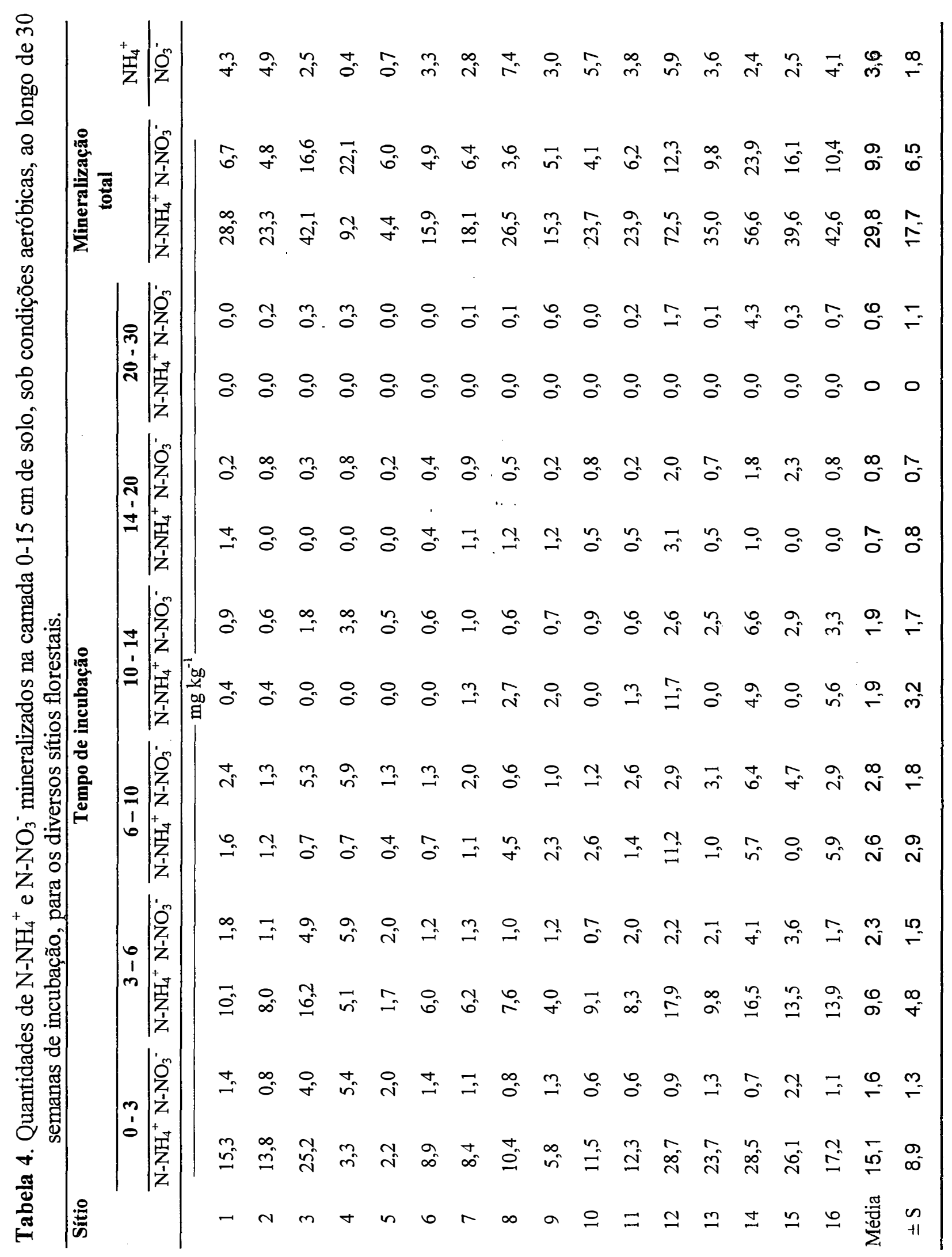


Tabela 5. Quantidades de N-NH${ }_{4}^{+}$mineralizados na camada $0-15 \mathrm{~cm}$ de solo, sob condições anaeróbicas, ao longo de 30 semanas de incubação, para os diversos sítios florestais.

\begin{tabular}{|c|c|c|c|c|c|c|c|}
\hline \multirow[t]{2}{*}{ Sítio } & \multicolumn{6}{|c|}{ Tempo de incubação (semanas) } & \multirow{2}{*}{$\begin{array}{c}\text { Mineral } \\
\text { total }\end{array}$} \\
\hline & 0 - 3 & $3-6$ & $6-10$ & $10-14$ & $14-20$ & $20-30$ & \\
\hline & & & & $\mathrm{ng} \mathrm{kg}{ }^{-1}$ & & & \\
\hline 1 & 16,3 & 9,3 & 7,3 & 5,8 & 2,4 & 2 & 43,1 \\
\hline 2 & 21,4 & 9,4 & 5,9 & 2,5 & 1,3 & 3,5 & 44,0 \\
\hline 3 & 42,8 & 45,3 & 35,8 & 23,6 & 7,5 & 11,8 & 166,8 \\
\hline 4 & 51,2 & 18,8 & 14,6 & 10,1 & 6,3 & 4,5 & 105,5 \\
\hline 5 & 24,1 & 31 & 16,6 & 2,7 & 1,9 & 0 & 76,4 \\
\hline 6 & 17,5 & 7,3 & 6 & 4,4 & 1,9 & 1,3 & 38,4 \\
\hline 7 & 37,8 & 26,5 & 20,4 & 11,8 & 4,1 & 4,1 & 104,7 \\
\hline 8 & 39,6 & 28,2 & 19,9 & 11 & 3,3 & 5 & 107,0 \\
\hline 9 & 25,9 & 18 & 13,6 & 8,7 & 2,5 & 3,7 & 72,5 \\
\hline 10 & 19,2 & 13 & 9 & 4,9 & 2,9 & 1,2 & 50,1 \\
\hline 11 & 24,8 & 16,7 & 11,6 & 5,7 & 1,4 & 2,5 & 62,7 \\
\hline 12 & 69,8 & 52,6 & 51,9 & 51,4 & 28,2 & 14,7 & 268,6 \\
\hline 13 & 33,4 & 12,9 & 10,9 & 9 & 4,5 & 4,4 & 75,0 \\
\hline 14 & 67,1 & 49,2 & 45,4 & 42,2 & 19 & 26,5 & 249,4 \\
\hline 15 & 49,8 & 35,5 & 31,2 & $.26,5$ & 9,6 & 11,1 & 163,8 \\
\hline 16 & 53,6 & 38,5 & 37,7 & 38,7 & 21,2 & 24,5 & 214,3 \\
\hline Média & 37,1 & 25,8 & 21,1 & 16,2 & 7,4 & 7,6 & 115,1 \\
\hline$\pm \mathrm{S}$ & 17,3 & 14,9 & 14,7 & 15,6 & 8,2 & 8,1 & 75,2 \\
\hline
\end{tabular}


Quanto mais superficial a camada de solo, maiores foram as quantidades de $\mathrm{N}$ mineralizadas, particularmente, nos sítios onde havia a presença de florestas nativas ( sítios 3, 4, 6, 12 e 16) (Tabelas 6 e 7). Por exemplo, sobre condições anaeróbicas, em média, $53 \pm 11 \%$ do $\mathrm{N}_{\mathrm{m}}$ ocorreu na camada $0-5 \mathrm{~cm}$ de solo e, $47 \pm 11 \%$ do $\mathrm{N}_{\mathrm{m}}$ na camada 10-15 cm de solo. Os menores valores de $\mathrm{N}_{\mathrm{m}}$ na camada superficial foram observados em sítios mais modificados pela atividade agrícola ou florestal (Ex..: sítios 5 e 13). Isto caracteriza a grande importância da ciclagem biogeoquímica, principalmente através da decomposição de raízes finas e serapilheira, sobre a elevação e/ou reposição das reservas de N potencialmente mineralizável (Gonçalves 1995). 
Tabela 6. Taxas de mineralização de $\mathrm{N}$ pela incubação aeróbica dos solos nos diversos sítios florestais.

\section{Sítio}

\section{-}


Tabela 7. Taxas de mineralização de $\mathrm{N}$ pela incubação anaeróbica dos solos nos diversos sítios florestais

Sítio

\begin{tabular}{|c|c|c|c|c|c|c|c|}
\hline \multirow[b]{2}{*}{$\mathbf{0}-\mathbf{3}$} & \multicolumn{4}{|c|}{ Semanas de incubação } & \multirow[b]{2}{*}{$20-30$} & \multirow[t]{2}{*}{$\mathbf{N}_{m}^{(1)}$} & \multirow{2}{*}{$\frac{N_{m}(0-5)}{N_{m}(0-15)}$} \\
\hline & $3-6$ & $6-10$ & $10-14$ & $14-20$ & & & \\
\hline \multicolumn{6}{|c|}{$\mathrm{mg} \mathrm{kg}^{-1} \operatorname{semana}^{-1}$} & $m g \mathrm{~kg}^{-1}$ & $\%$ \\
\hline \multicolumn{6}{|c|}{ Profundidade $0-5 \mathrm{~cm}$} & & \\
\hline 2,6 & 2,3 & 1,1 & 0,6 & 0,1 & 0,1 & 23,6 & 55 \\
\hline 3,2 & 2,2 & 1,1 & 0,6 & 0,1 & 0,3 & 27,0 & 61 \\
\hline 7,7 & 9,5 & 5,7 & 4,1 & 0,9 & 0,8 & 103,9 & 62 \\
\hline 8,1 & 3,8 & 2,3 & 1,6 & 0,5 & 0,4 & 58,6 & 56 \\
\hline 3,2 & 0,7 & 0,4 & 0,3 & 0,2 & 0,0 & 15,6 & 20 \\
\hline 2,9 & 1,0 & 0,7 & 0,6 & 0,2 & 0,1 & 19,2 & 50 \\
\hline 5,6 & 4,5 & 2,9 & 2,3 & 0,5 & 0,4 & 58,2 & 56 \\
\hline 8,4 & 2,9 & 1,9 & 1,5 & 0,3 & 0,3 & 53,1 & 50 \\
\hline 5,6 & 4,5 &, 5 & $1 ; 5$ & 0,3 & 0,2 & 50,1 & 69 \\
\hline 2,9 & 1,3 & 0,9 & 0,7 & 0,4 & 0,1 & 22,1 & 44 \\
\hline 3,4 & 3,6 & 1,9 & 0,9 & 0,1 & 0,3 & 35,4 & 56 \\
\hline 12,7 & 10,7 & 7,7 & 7,5 & 2,8 & 0,4 & 152,0 & 57 \\
\hline 5,0 & 2,2 & 1,5 & 1,2 & 0,3 & 0,3 & 37,4 & 50 \\
\hline 11,1 & 8,1 & 5,4 & 5,0 & 1,7 & 1,2 & 121,7 & 49 \\
\hline 9,4 & 6,2 & 4,5 & 4,3 & 1,1 & 0,7 & 96,0 & 59 \\
\hline 9,2 & 6,1 & 4,9 & 5,6 & 2,0 & 1,5 & 114,4 & 53 \\
\hline 6,3 & 4,4 & 2,7 & 2,4 & 0,7 & 0,4 & 61,8 & 53 \\
\hline 3,3 & 3,0 & 2,2 & 2,2 & 0,8 & 0,4 & 42,5 & 11 \\
\hline
\end{tabular}

Profundidade 5 - $15 \mathrm{~cm}$

$\underline{N}_{\mathbf{m}}(\mathbf{5}-15)$

$N_{m}(0-15)$

$\%$

45

$\begin{array}{llllllll}2,9 & 0,8 & 0,7 & 0,8 & 0,3 & 0,1 & 19,7 & 45\end{array}$

$\begin{array}{llllllll}3,9 & 1,0 & 0,3 & 0,1 & 0,1 & 0,0 & 17,0 & 39\end{array}$

$6,6 \quad 5,6 \quad 3,3 \quad 1,8 \quad 0,4$

$0,4 \quad 63,0 \quad 38$

$9,0 \quad 2,4 \quad 1,4 \quad 1,0 \quad 0,5$

$0,0 \quad 47,0$

44

$3,7 \quad 0,4 \quad 0,1$

0,0

60,9

80

$3,0 \quad 1,5$

0,8

0,5

0,1

0,0

19,4

50

$7,0 \quad 4,3$

2,2

0,6

0,0

46,6

44

3,0

0,2

0,2

54,0

50

$\begin{array}{ll}4,9 & 6,5 \\ 3,1 & 1,5\end{array}$

0,9

0,6

0,2

22,6

31

1,4

0,2

0,0

28,0

56

$4,8 \quad 1,9$

1,0

0,5

0,0

27,3

44

5,3

5,3

1,1

116,6

43

$6,2 \quad 2,1 \quad 1,2$

1,0

0,1

37,8

50

5,9

5,5

1,4

127,7

51

$\begin{array}{ll}7,2 & 5,6\end{array}$

3,3

2,3

0,4

67,8

41

16

$8,7 \quad 6,7$

4,5

4,1

0,5

1,0

99,9

47

Média

6,1

4,2

2,4

1,6

0,3

53,5

47

1,8

1,8

0,6

0,5

34,9

11 


\section{Conclusões}

v As quantidades acumuladas de $\mathrm{N}$ mineralizado, em condições aeróbicas e anaeróbicas, mostrou uma relação exponencial com o tempo de incubação.

v A equação $N_{t}=N_{0}+$ b/t ajustou-se melhor aos dados do que a equação proposta por Stanford \& Smith (1972), $N_{t}=N_{0}\left(1-e^{-k t}\right)$.

v As taxas de mineralização de $\mathrm{N}$ estabilizaram após 8 a 15 semanas de incubação.

v As quantidades totais de $N_{0}$, sob condições aeróbicas, variaram entre $103 \pm$ $53 \mathrm{~kg} \mathrm{ha}^{-1}$ de $\mathrm{N} \mathrm{e}$, sob condições anaeróbicas, entre $281 \pm 175 \mathrm{~kg} \mathrm{ha}^{-1} \mathrm{de} \mathrm{N}$.

- Estima-se que as reservas médias de $\mathrm{N}$, dos sítios pesquisados, são suficientes para 3 a 5 rotações ( 7 anos cada) de cultivo de $E$. grandis.

y Em alguns sítios, a presença da mata nativa redundou em maiores quantidades de $\mathrm{N}$ potencialmente mineralizável.

y A floresta adulta de eucalipto foi capaz de manter no solo níveis de $N_{0}$ similares ao da floresta nativa.

- A razão média $\mathrm{N}-\mathrm{NH}_{4}^{+}: \mathrm{N}^{-} \mathrm{NO}_{3}{ }^{-}$, foi igual a $4: 1$ sob condições aeróbicas. 


\section{REFERÊNCIAS BIBLIOGRÁFICAS}

ALEXANDER, M. Mineralization and immobilization of nitrogen. In: ALEXANDER, M. ed Introduction to soil microbiology. $4^{\text {a }}$ ed. New York, John Wiley, 1967. P.248-271.

ATTIWILL, P. M. \& LEEPER, G. W. Forest soils and nutrient cycles. Melbourne University Press: Carlton, 1987. 202 p.

BARROS, N.F., NOVAIS, R.F. \& NEVES, J.C.L. Fertilização e correção do solo para o plantio de eucalipto. In: BARROS, N.F. \& NOVAIS, R.F. ed. Relação SoloEucalipto. Ed. Folha de Viçosa, Viçosa. 1990, p.p.127-186.

BELlOTE, A.F.J., SARRUGE, J.R., HAAG, P.H. \& OLIVEIRA, G.D. Extração e exportação de nutrientes pelo Eucalyptus grandis Hill, ex-Maiden em função de idade: 1 -Macronutrientes. IPEF, Piracicaba, 20:1-23, 1980.

BINKLEY, D.; HART, S.C. The components of nitrogen availability assesments in forest soils. In: STEWART, B.A. Advances in Soil Science. New York, Springer Verlag, 1989.200p.

BLACK, C. A. Soil- plant relationship. 2 ed. New York, John Wiley, 1968. 419 - 452p.

CABRERA, M. L.; KISSEL, D. E. Potentially mineralizable nitrogen in disturbed and indisturbed soil samples. Soil Sci. Soc. Am. J., Madison, 52:1010-1015, 1988.

CARLYLE, J. C.; LOWTHER, J. R.; SMETHURST, P. J.; NAMBIAR, E. K. S. Influence of chemical properties on nitrogen mineralization and nitrification in 
podzolized sands. Implications for forest management. Aust. J. Soil Res., 28:9811000,1990 .

CARSKI, T. H.; SPARTS, D. L. Differentiation of soil nitrogen fractions using a kinetic approach. Soil Sci Soc. Am J. , Madison, 51:314 - 317, 1987

CORNFORTH, I.W.; WALMSLEY, D. Methods of measuring available nutrients in West Indian soil. Plant Soil, The Hague, 35: 389-399, 1971.

CRASWELL, E. T., WARING, S. A. Effect of grinding on the decomposition of soil organic matter. I. The mineralization of organic nitrogen in relation to doil type. Soil Biol. Biochem. 4L:427 - 433, 1972.

DEANS, J. R.; MOLINA, J. ${ }^{\text {a }}$ E.; CLAPP, C. E. Models for predicting potentially mineralizable nitrogen and decomposition rates constantes. Soil Sci. Soc. Am. J., Madison, 50::323 - 326, 1986.

EMBRAPA - Empresa de Pesquisa Agropecuária. Manual de Métodos de Análise de Solo. Rio de Janeiro: Rio de Janeiro, 1997. 212p.

FLINN, D. W. , SQUIRE, R. O.; FARRELL, P. W.. The role of organic matter in the maintenance of site productivity on sandy soils. New Zaland Jornal Forest, 52:226- 229, 1980.

FLINN, D. W.; HOPMANS, P.; FARRELL, P. W.; JAMES, J. M. Nutrient loss from the burning of Pinus radiata logging residue. Aust. For. Res. 9:17-24, 1979.

GIANELlO, C., CAMARGO, F. A. O.; VIDOR, C. Subestimação do nitrogênio potencialmente mineralizávell do solo. In: XXV CONGRESSO BRASILEIRO DE CIÊNCIA DO SOLO, Viçosa, 23 a 29 de julho, p. 708-709,1995.

GONÇALVES, J.L.M. Efeito do cultivo mínimo sobre a fertilidade do solo e ciclagem de nutrientes. In: DISPERATI, A.A.; FERREIRA, C.A.; MACHADO, C.; GONÇALVES, J.L.M. \& SOARES, R.V. $1^{\circ}$ Seminário Sobre Cultivo Mínimo do Solo em Florestas. Curitiba, p. 43-60.1995 
GONÇALVES, J.L.M.; BARROS, N.F.; NAMBIAR, E.K.S.; NOVAIS, R.F. Soil and stand management for short-rotation plantations In: NAMBIAR, S. \& BROWN, A. (Eds.) Management of soil, nutrients and water in tropical plantation forests. Camberra, ACIAR Austrália/CSIRO Austrália/CIFOR Indonésia, 1997a. 571 p. cap. 11. pp. 379-418.

GONÇALVES, J.L.M.; CARLYLE, J.C. Modelling the influence of moisure and temperature on net nitrogen in a forested sandy soil. Soil Biology and Biochemistry, 26:1557-1564, 1994.

GONÇALVES, J.L.M.; POGGIANI, F.; STAPE, J.L.; SERRANO, M.I.P.; MELLO, S.L.M.; MENDES, K.C.F.S.; BENTIVINHA, S.R.P.; OLIVEIRA, L.E.G. Efeito de práticas de cultivo mínimo e intensivo do solo sobre a ciclagem de nutrientes, fertilidade do solo, configuração do sistema radicular e nutrição mineral de povoamentos de Eucalyptus grandis. Piracicaba: ESALQ, Departamento de Ciências Floretais, 1997. 83p. (Relatório para a FAPESP, processo $\mathrm{n}^{\mathrm{0}}$ 1994/4248-7, 83p. 1997b).

HADAS, S. C. ; FEIGENBAUM, S., FEIGIN, A; PORTNOY. Nitrogen mineralization in profiles of differently managed soil type. Soil Sci. Soc. AM. J., Madison, 50: 314-319, 1986.

HART, S.C.; BINKLEY, D. Correlations among indices of forest soil nutrient availability in fertilized and unfertilized lobloly pine plantations. Plant and Soil, The Hague, 85:11-21, 1985.

HERBERT, M.A.; SCHÖNAU, A.P.G. Fertilising Commercial forest species in Southern Africa: research progress and problems (part 2). South Afr. For. J., 152:34-42, 1990.

HERLILY, M. Nitrogen mineralization in soils of varyng texture, moisture and organic matter. Plant Soil, 53:255-267, 1979 
HIURA, K.; HATTORI, T; FURUSAKA, C. Bacteriological studies on the mineralization of organic nitrogen in paddy soil. I Effects of mechanical disruption of soil on ammonification and bacterial number. Soil Sci. Plant. Nutr. Tokio, 22:459465,1976

I.B.G.E. Mapa de vegetação do Brasil. DERNA, Rio de Janeiro, 2ª impressão, 1995.

JANSSON, S. L. Tracer studies on nitrogen transformation in soil with special attention to mineralization - immobilization relationships. Kunliga Lantbrukshogskolans Annaler, 24: 100-361, 1958.

KEENEY, D. R.; BREMNER, J. M. Comparison and evaluation of laboratory methods of obtaining an index of soil nitrogen availability. Agron. J., 58:498-503, 1966.

KEENEY, D.R. Nitrogen - Availability indices. In: PAGE, A.L., MILLER, R.H. \& KEENEY, D.R. (Ed.) Methods of soil analysis (Parte 2) - Chemical and Microbiological properties. $2^{\circ}$. edition, Am. Soc. of Agronomy., Madison, 1982. pp 711-733.

LAMB, D. Soil nitrogen mineralization in a secundary rainforest succession. Oecologia, Berlim, 47: 257 - 263, 1980.

LEMOS, E.E.P.; SALCEDO, I.H.; SAMPAIO, E.V.S.B. Comparação entre o N mineralizado através de incubações com e sem percolação e o $\mathrm{N}$ absorvido pelo milheto em solo podzólico vermelho-amarelo. R. Bras. Ci. Solo, Campinas, 12: 127-130, 1988.

MARION, G. M.; KUMMEEROW, J.; MILLER, P. C. Predicting nitrogen mineralization in Chaparral soils. Soil Sci. Soc. Am. J. , Madison, 45:956-961, 1981

McGILL, W. B.; CHRISTIE, E. K. Biogeochemical aspects of nutrient cycle interations in soils and organisms, In: BOLIN, B.; COOK, R. B., Eds. The major biogeochemical cycles and their interations. New York, John Wiley \& Sons, p.271-301, 1983. 
NADELHOFFER, K.J.; ABER, J.D.; MELILLO, J M. Leaf litter production and soil organic matter dynamics along a nitrogen - availability gradient in Southern Wiscousin (USA). Canadian Journal of Forest Research, Ottawa, $13: 12-21$, 1983.

OSBORNE, G.F; STORRIER, R.R. Influence of different sources of nitrogen fertilizer on the value of soil nitrogen tests. Aust. J. Exp. Agric. Anim. Husb., 16: 881-886, 1976.

OYANEDEL, C.; RODRIGUEZ, J. S. Estimación de la mineralización del N en el suelo. Ciencia e Inv. Agraria. Santiago, 4:33-34, 1977

PAUL, E. A., \& JUNA, N. G. Mineralization and immobilization of soil nitrogen by microorganisms. In: Terrestrial Nitrogen Cycles. Processes, Ecosystem Strategies and Management Impacts. (Eds F. E. Clark and T. Rosswall). Ecological Bolletin (Stockholm) 33, 179-195, 1981.

PARENTONI, S. N., FRANÇA, G. E. ; BAHIA FILHO, A. F. C. Avaliação dos conceitos de quantidade e intensidade de mineralização de nitrogênio para trinta solos do Rio Grande do Sul. Revista Brasileira de Ciência do Solo, Campinas, 12: 225-229, 1988.

POGGIANI, F. Ciclagem de nutrientes em ecosistemas de plantações florestais de Eucalyptus e Pinus. Implicações silviculturais. ESAL/USP, Piracicaba. 1985, 210p. (Tese de Livre Docência, ESALQ/USP)

POTTKER, D.; TEDESCO, M. J. Efeito do tipo e tempo de incubação sobre a mineralização da matéria orgânica e nitrogênio total em solos do Rio Grande do Sul. Revista Brasileira de Ciencia do Solo, Campinas, 3:20-24,1979.

RAIJ, B. van; QUAGGIO, J. A.; CANTARELLA, H.; FERREIRA, M. E. LOPES, A. S.; BATAGLIA, O. C. Análise química de solo para fins de fertilidade. Campinas: Fundação Cargill, 1987. 170p. 
RAISON, R.J.; CONNELL, M.J.; KHANNA, P.K. Methodology for studying fluxes of soil mineral-N in situ. Soil Biology Biochemistry, Oxford, 19: 521-530, 1987.

RAISON, R.J.; CONNELL, M.J.; KHANNA, P.K. Methodology for studying fluxes of soil mineral-N in situ. Soil Biology Biochemistry, Oxford, 19: 521-530, 1987.

REIS, M. G. F.; BARROS, N.F. \& Kimmins, J.P. Acúmulo de nutrientes em uma seqüência de idade de Eucalyptus grandis W. Hill ( ex - Maiden ) plantado no cerrado, em duas áreas com diferentes produtividades, em Minas Gerais. Revista Árvore, Viçosa, 11 (1): 1-15, 1987.

RUZICKA,J.; HANSEN, E.H. Flow injection anaysis. Part I. The concept of a new, simple, ultrafast continuous flow analyser. Analitica Chimica Acta, v. 78, p. 145157, 1975.

RYAN, J.A.; SIMS, J.L.; PEASLEE, D.E. Laboratory methods for estimating plant available nitrogen in soil. Agron. J., 63:48-51, 1971.

SALCEDO, I.H.; SAMPAIO, E.V.S.B.; ALVES, G. D. Mineralização do carbono e do nitrogênio em solo cultivado com cana-de-açucar. Revista Brasileira de Ciencia do Solo, Campinas, 9:33-38,1985.

SERRANO, M. I. P. Mineralização, absorção e lixiviação de $\mathrm{N}$ em povoamentos de Eucalyptus grandis sob cultivo mínimo e intensivo do solo.. Piracicaba,1997.86p. Dissertação (M.S.) Escola Superior de Agricultura "Luiz de Queiroz"

SIMS, J.L.; BLACKMON, B.G. Predicting nitrogen availability to rice: II. Assessing available nitrogen in silt loams with different previous year crop history. Soil Sci. Soc. Am. Proc., Madison, 31: 676-680, 1967.

SIMS, J.L.; WELLS, J.P.; TACKETT, D.L. Predicting nitrogen availability to rice: I. Comparison of methods for determining available nitrogen to rice from field and reservoir soils. Soil Sci. Soc. Am. Proc., Madison, 31: 672-676, 1967. 
SMETHURST, P. J.; NAMBIAR, E. K. S. Distribution of carbon and nutrients and fluxes of mineral nitrogen after clear-felling a $P$. radiata plantation. Can. J. For. Res., 20:1490-1497, 1990.

SMETHURST, P.M. \& NAMBIAR, E.K.S. Effects of slash and litter management on fluxes of nitrogen and tree growth in young Pinus radiata plantation. Canadian Journal Forest Research, Ottawa, 20: 1500- 1507, 1990.

STANFORD, G.; CARTER, J. N.; WESTERMANN, D. T.; MEISINGER, J. J. residual nitrate and mineralizable soil nitrogen in relation uptake by irrigate sugarbeets. Agron. Journal, 69:303-308, 1977

STANFORD, G.; LEGG, J.D. \& SMITH, S.J. Soil nitrogen availability evaluation based on nitrogen mineralization potencials and uptake of labeled and unlabeled nitrogen by plant. Plant Soil , Hague, 39: 113-124, 1973.

STANFORD, G.; SMITH, S. J. Nitrogen mineralization potencials of soil. Proc. Soil Sci. Soc. Am. J. , Madison, 36:465-472, 1972.

VERSTRAETE, W. ; VOETS, J. P. Nitrogen mineralization tests and potentials in relation to soil management. Pedologie, 26:15-26.

WARING, S.A.; BREMNER, J.M. Ammonium production in soil under waterlogged conditions as an index of nitrogen availability. Nature, London, 201: 951-952, 1964.

WHYNOT, T. N. \& WEETMAN, G. F. Repeated fertilization effects on nitrogen fluxes measured by sequencial coring. Soil Sci. Soc. of American Journal, Madison, 55:1101-111, 1991. 